\title{
Os Anos 80: A Politização do Sangue*
}

\author{
LUIZA. DE CASTRO SANTOS \\ CLÁUDIA MORAES \\ VERA SCHATTAN P. COELHO**
}

\begin{abstract}
"E me vejo perplexo no entrechoque de tendências e grupos, todos querendo salvar o Brasil e não sabendo como, ou sabendo demais."

Carlos Drummond de Andrade (1945)***
\end{abstract}

Este trabalho tem um duplo objetivo. Primeiramente, apresentar uma descrição e análise da hemoterapia no Brasil durante os últimos dez anos, a partir do lançamento do plano governamental Pró-Sangue, de 1980. Em segun-

* Este trabalho é o segundo de uma série dedicada à questão do sangue no Brasil, baseado em pesquisa conduzida no Cebrap, em São Paulo, durante o ano de 1989, com financiamento da Finep e da Secretaria de Ciência e Tecnologia do Estado de São Paulo. Os autores são inteiramente responsáveis pelas análises e conclusões apresentadas. $\mathrm{O}$ primeiro artigo, também de autoria de L.A. Castro Santos, C. Moraes e V.S. Pereira Coelho, "A Hemoterapia no Brasil de 64 a 80", foi publicado em Physis (1) 1, 1991: 161-181.

** Luiz Antonio de Castro Santos é professor adjunto do Departamento de Ciências Humanas e Saúde do IMS/UERJ e pesquisador licenciado do Cebrap. Cláudia Moraes é doutoranda em antropologia no Museu Nacional/UFRJ. Vera Schattan Pereira Coelho é pesquisadora do NEPP/UNICAMP e consultora da FUNDAP.

*** Citado em Francisco Iglésias, "A recusa da biografia". Folhetim, Folha de São Paulo, 21.08.1987, p.B-4. 
do lugar, criticar a radicalização estéril que tem caracterizado tanto a ação como o pensamento de boa parte dos grupos profissionais, movimentos sociais, partidos políticos e organizações governamentais e não governamentais envolvidos com a questão do sangue no Brasil. A nosso ver, o necessário debate político em torno da questão ressentiu-se da falta de uma base técnica sólida (desconhecimento dos próprios dados do setor e da diversidade regional da hemoterapia no País) e da escassa ou nenhuma familiaridade com a literatura internacional sobre as experiências de outros países. Na verdade, o dilema da estatização versus privatização acabou por recobrir excessivamente todo o debate técnico e político e por conferir a uma questão complexa uma simplicidade inaceitável.

Em trabalho anterior, ${ }^{1}$ procuramos analisar o surgimento, no Brasil, da hemoterapia como uma questão de política pública e interesse social. Em linhas gerais, o trabalho focalizou o modo pelo qual o segundo pós-guerra viu brotar no Brasil, a partir do impulso inicial dos países beligerantes, uma preocupação crescente com as necessidades de captação, estocagem e distribuição de sangue humano, que se traduziu nas primeiras leis de regulamentação da hemoterapia e na formação de associações de estímulo à doação voluntária não remunerada - epíteto que se tornou necessário diante das práticas de "doação" remunerada. Uma entidade importante, a Sociedade Brasileira de Hematologia e Hemoterapia (SBHH), foi criada em 1950, congregando profissionais da área.

$\mathrm{O}$ trabalho citado esclareceu, ainda, que foi sob o regime militar que o setor se tornou objeto de maior atenção governamental, através de uma Política Nacional do Sangue (1965). Em parte, esta política resultou da preocupação dos militares, logo após o golpe, com a falta de uma reserva hemoterápica no país em caso de conflito armado. Por outro lado, o incentivo à atividade industrial, de produção de derivados de sangue, desempenhou importante papel no aparecimento de uma política nacional no início do governo militar.

Indicou-se ainda, em nosso trabalho, que os rumos tomados pelo "disciplinamento" do setor não impediram — de certa forma, chegaram mesmo a estimular - a baixa qualidade dos serviços. A política de saúde do governo militar, entendida em sentido amplo, produziu efeitos danosos sobre a hemoterapia. A partir de 1967, os órgãos da Previdência unificada passaram a comprar sangue de bancos particulares para uso em hospitais públicos e conveniados. Iniciou-se assim, a partir de tais condições favoráveis, a especulação com o sangue através da exploração de doadores "voluntários" de baixa renda por um

1 Ver nota introdutória. 
sem-número de proprietários de pequenos bancos de coleta, operando sem ética, sem padrões profissionais e sem fiscalização. Note-se que a atividade hemoterápica séria floresceu em hospitais particulares, em alguns centros (particularmente em São Paulo), mas a confiabilidade dos serviços nunca foi regra no setor.

Esta foi, em linhas gerais, a evolução do setor até 1980. Quanto ao panorama mais amplo no país, que norteou aquela evolução, assinale-se que a crise econômica durante a segunda metade da décade de 70 afetou a área dos serviços de saúde e provocou protestos da população desassistida, a que se aliąram os movimentos de resistência da própria corporação médica, tanto nas faculdades de medicina e centros de pesquisa como em sindicatos e associações.

A criação do Pró-Sangue (Programa Nacional do Sangue) em 1980, articulando órgãos dos Ministérios da Saúde e da Previdência e propondo a total reorganização da atividade hemoterápica, pode ser vista como uma resposta oficial à crescente insatisfação da sociedade organizada com o descontrole do sistema. Os altos índices de contaminação sanguínea - particularmente a ocorrência de Chagas transfusional - constituíam uma das razões de constestação ao sistema de saúde na virada da década. Entretanto, como se verá a seguir, o Pró-Sangue (ou mesmo o Planashe - Plano Nacional de Sangue e Hemoderivados, nova denominação do programa em 1988) teria provavelmente esbarrado nos obstáculos que afetaram a saúde pública e a atenção médico-previdenciária durante os anos seguintes - em que avultaram a redução de recursos e a paralisia institucional ${ }^{2}$ - não fosse o aparecimento da Aids no Brasil.

Os primeiros casos de Aids diagnosticados configuraram um fato social de extrema ressonância no país. O grande medo social por ela provocado (para lembrar a expressão de Michael Pollak) provocou uma gradual polarização da opinião pública e dos movimentos sociais em torno do Pró-Sangue, e mais tarde do Planashe. No compasso das pressões que se originavam da própria sociedade ao longo de toda a década, respondeu a política oficial, ainda que de modo errático ou irregular. A eficácia de tais pressões foi uma característica singular da política hemoterápica, em contraste à lógica de formulação da política de saúde dos anos 80. Diríamos mesmo que nenhum momento da evolução quase centenária das reformas sanitárias no Brasil revelou tal permeabilidade da política estatal às pressões da sociedade. A Aids transfusional, ao disseminar o "grande medo" e aglutinar um amplo movimento de luta pela melhoria dos serviços, foi responsável pelos rumos da política nacional do sangue na década

2 Para uma análise das políticas de saúde durante os anos 80, consulte-se: Madel Therezinha Luz, "Notas sobre as políticas de saúde no Brasil de 'transição democrática' - anos 80", Physis (1) 1: 77-96. 
de 1980 e até nossos dias. (Foi este também, em graus variáveis, o impacto da ocorrência da Aids transfusional sobre os novos rumos da hematologia e da hemoterapia nos países do Primeiro Mundo.)

\section{Os novos rumos}

O início dos anos 80, diante da persistência da crise fiscal do Estado brasileiro, reacendeu o antigo debate sobre setor público e setor privado no país. Este debate se politizou cada vez mais ao longo da década, ganhando o espaço da sociedade civil. A própria atenção dada ultimamente ao problema do sangue no Brasil, como um tópico da extensa pauta de discussões levantada pela Aids, acirrou e aprofundou esse debate.

Os progressos da hemoterapia, tanto em pesquisa científica como em estrutura organizacional, costumam ser vinculados à guerra (e já se viu como o receio de um conflito armado despertou o governo militar para a questão do sangue e o levou a realizar as primeiras tentativas de organizar o setor). No entanto, no Brasil como em outros países, não foram guerras as responsáveis pelos progressos dessa década. A Aids foi recebida como a catástrofe que tornou inadiável a tão necessária e sempre postergada reestruturação dos serviços hemoterápicos. Os profissionais do setor apontam a força deste impacto: "Então em 1981 surgiu o que eles chamam o Cavaleiro do Apocalipse. A Aids veio. Foi a bomba atômica da hemoterapia" (Guido de Azevedo, chefe do serviço de hemoterapia do INCA). "Nos últimos vinte ou trinta anos houve um descaso, aliado a uma incompetência e a uma coisa que me parece mais ou menos voluntária, que é manter as atividades hemoterápicas meio subterrâneas, isto é, longe do controle e da fiscalização. E o que a Aids faz é desnudar, tirar o véu" (Sílvia Ramos, secretária-executiva da ABIA). "Foi a Aids que trouxe uma conscientização maior para a questão do sangue, inclusive quanto à questão da profissionalização" (Paulo Machado, diretor do hemocentro de Botucatu). ${ }^{5}$ "É pacífico que o debate sobre o sangue se tornou premente porque a Aids transmitida é uma doença terrível, fatal, e aí vem o pânico geral" (Laerte Vaz de Mello, presidente do CREMERJ). ${ }^{6}$ "A Aids criminalizou o sangue, porque é mortal" (Herbert de Souza, presidente da ABIA). ${ }^{7}$ Todos aqueles ligados ao

\footnotetext{
3 Entrevista ao Cebrap em 1/7/88.

4 Entrevista ao Cebrap em 30/6/88.

5 Entrevista ao Cebrap em 15/4/88.

6 Entrevista à TEMA 10.

7 Entrevista à TEMA 10.
} 
setor têm consciência de que os problemas existem desde longa data, e que as doenças antes já transmitidas, como a hepatite B e doença de Chagas, podem ser mortais a longo prazo. Mas a Aids veio criar uma situação-limite, fazendo com que os problemas do sangue despertassem o interesse público, passando a figurar nas primeiras páginas dos jornais.

A resposta institucional, no plano das políticas públicas, foi lenta e aos trancos, sendo difícil apontar uma correlação linear entre a repercussão da Aids como fato social e a reorganização da hemoterapia. Um fator interveniente foi o próprio nível de complexidade do "setor saúde" em cada estado. O estado de São Paulo, onde o nível tecnológico e a organização dos serviços de saúde apresentam maior complexidade, possuía as condições favoráveis para uma resposta oficial mais rápida ao clamor público por mudanças na seleção de doadores, testagem, fiscalização, pesquisa etc. Se descontarmos a diversidade regional, o impacto da Aids sobre a hemoterapia no país como um todo (e mesmo em países capitalistas avançados, como a França) só ocorreu a partir de 1985. No Brasil, foi o início da chamada Nova República.

Atente-se para o fato de que, com o fim do regime militar, antigos militantes das lutas pela reforma sanitária ocuparam cargos-chave do aparelho médico-previdenciário do Estado. A grande repercussão do problema do sangue veio a ocorrer em meio às discussões prévias sobre a Reforma Sanitária, à realização da oitava Conferência Nacional de Saúde em 1986, à implantação do Sistema Unificado e Descentralizado de Saúde (SUDS) e às votações da Constituinte, respectivamente em 1987 e 1988 . O controle do sangue passou a ser um dos pólos do debate sobre estatização/privatização dos serviços de saúde, aparecendo muitas vezes como um exemplo das necessidades de reformulação do sistema de saúde brasileiro. Sérgio Arouca, presidente da Fiocruz, criticava, na edição de 1/5/88 da Folha de S. Paulo, aqueles que defendiam na Constituinte a comercialização do sangue: "É aquela parte de empresários que se locupletou com a mercantilização, é um setor dependente, sempre atrelado ao Estado, que construiu hospitais com recursos estatais a fundo perdido, responsável pelo Brasil ser o campeão de cesarianas e ter a qualidade de sangue que tem."

$\mathrm{Na}$ esteira da política oficial de descentralização da estrutura dos serviços de saúde, e também por causa da ausência de medidas efetivas na área por parte do governo federal, alguns estados começaram a formular uma política hemoterápica própria. Foi o que aconteceu em São Paulo e (com maiores percalços) no Rio de Janeiro, onde, no final de 1987, criaram-se grupos encarregados de traçar uma política específica para enfrentar os problemas de sangue em cada um desses estados. Paralelamente a este planejamento, intensificou-se a fiscalização dos serviços de hemoterapia por parte das divisões de Vigilância 
Sanitária, e leis estaduais foram decretadas para suprir a carência ou morosidade da iniciativa federal. O Rio de Janeiro saiu na frente, proibindo a doação remunerada em 1985 (resolução 344). As autoridades paulistas estabeleceram, em junho de 1986, a obrigatoriedade do teste anti-Aids em todo sangue utilizado para fins hemoterápicos (lei estadual 5190), adiantando-se em um ano e meio à determinação federal neste sentido. A respeito, afirmou Cármino de Souza, coordenador do Programa de Hematologiae Hemoterapia de São Paulo ("Gepro do Sangue"): "Armamos uma estratégia de guerra: em um mês conseguimos botar testes para todo o estado de São Paulo. Nenhum sangue em São Paulo fica sem sorologia para Aids." 8

Com a política para o setor sendo conduzida principalmente pelos estados, a situação da hemoterapia no Brasil tornava-se mais heterogênea. Enquanto no Rio e em São Paulo a fiscalização e os processos instaurados por vítimas de contaminação faziam com que se estabelecessem certo controle sorológico e maior atenção aos procedimentos hemoterápicos, em outros estados pouco se fazia, mesmo depois de janeiro de 1988, quando, por decreto federal, o teste anti-Aids passou a ser obrigatório na triagem do sangue. $\mathrm{O}$ ministro Borges da Silveira reconhecia a incompetência do seu ministério para garantir maior controle das atividades e declarava que o governo não teria capacidade de assumir o setor hemoterápico, caso a proibição da comercialização do sangue, aprovada pela Constituinte, fosse interpretada como estatização.

Outra inovação, além da "estadualização" das políticas do sangue (que precedia assim a descentralização prevista pelo SUDS), foi a mencionada pressão da sociedade civil sobre o governo. Organizações como a Associação Brasileira Interdisciplinar de Aids (ABIA), Associação Brasileira dos Hemofílicos, Associação Brasileira dos Talassêmicos, Grupo de Apoio à Prevenção à Aids (Gapa), Comitê Pacto de Sangue, Cremerj, Associação dos Médicos Sanitaristas de São Paulo, Sindicato dos Jornalistas de São Paulo, UNE e OAB exigiram, através da participação em atos, como o Fórum Estadual do Sangue no Rio de Janeiro e o Tribunal Henfil em São Paulo, medidas imediatas para que se eliminasse o descontrole do sangue no Brasil.

A luta pela proibição da comercialização do sangue na Constituinte é reveladora de que forças se mobilizaram pela questão, e das posições que assumiram. $\mathrm{O}$ debate, longe de apresentar novidades em termos de posições e argumentação (além da participação expressiva da sociedade civil), repisou velhas discussões pró- e antiestatização. A indústria de hemoderivados, a

8 Entrevista concedida ao Cebrap em 15/4/88. 
Sociedade Brasileira de Hematologia e Hemoterapia e a Federação Brasileira de Hospitais se posicionaram contra a proibição do comércio do sangue. A favor da proibição alinharam-se setores da medicina com antiga militância no chamado "partido sanitarista". Mais adiante veremos brevemente como a questão do sangue foi encaminhada e debatida na Constituinte de 1988.

\section{Os Problemas do Sangue depois da AIDS}

Os avanços conquistados a partir da chegada da Aids ao país, em ritmo irregular durante toda a década, não bastaram para eliminar do cenário nacional o espectro da doença transfusional.

As contaminações ocorridas através de transfusões ou do emprego de hemoderivados se ligam ao problema do controle sorológico do sangue utilizado para fins terapêuticos. Este problema permanece, talvez, como o mais grave, mas está longe de ser o único. A falta de controle não se refere apenas à sorologia, estendendo-se praticamente a todas as etapas do processo hemoterápico. Mas não resta dúvida de que o controle dos doadores de sangue é a primeira etapa do processo para se obter sangue de boa qualidade. A seleção dos candidatos à doação não pode ser feita apressadamente e por pessoal não treinado. Os candidatos à doação recusados por apresentarem sorologia positiva para alguma doença devem ser acompanhados medicamente, e os dados obtidos com os testes, comunicados à autoridade sanitária, como um precioso indicador de saúde da população. Permanece ainda, de modo geral, a necessidade de controle efetivo sobre a frequiência de doações, para que se evite que aqueles que doam por interesse o façam muito mais vezes do que seria recomendável, ao mesmo tempo em que se estimule o doador ocasional a fazer da doação uma atividade regular.

A falta de dados estatísticos referentes ao setor é consequiência do pouco tempo de controle ou de sua inexistência em muitos estados, tornando impossível uma vigilância efetiva, uma avaliação da rede instalada e a adoção de planos mais fundamentados em dados reais. Registros rasurados de doadores, resultados conflitantes de testes sorológicos, suspeitas de desvio de sangue colhido em hospitais públicos para a rede particular completam o quadro. Como resultado disso, não há certezas. "Estima-se" que as necessidades nacionais sejam de 5 milhões de bolsas (de 400 a $500 \mathrm{ml}$ de sangue), que a rede privada seja responsável por $70 \%$ do sangue coletado no país, que os $30 \%$ restantes, garantidos pela rede oficial de hemocentros, correspondam a menos de $10 \%$ das necessidades de transfusão, que a produção de hemoderivados no país cubra 
apenas $10 \%$ da demanda nacional, que $30 \%$ do sangue transfundido esteja fora de qualquer controle. ${ }^{9}$

Neste quadro de incerteza perduram as denúncias de contaminação, ainda que bastante reduzidas em alguns estados. A investigação de cada caso ocorrido geralmente revela uma estarrecedora série de irregularidades. Todo este quadro resulta da ausência, durante décadas, de uma efetiva fiscalização das atividades hemoterápicas por parte das autoridades sanitárias, em que pese a exigência legal de informação sobre registro do estabelecimento, doador, sorologia, soropositividade etc.

Além do descontrole, muitos são os problemas que perduram durante os anos 80 . Em primeiro lugar, há a falta constante de doadores. As campanhas pro-doação altruísta são de modo geral descontínuas e descoordenadas (cada entidade promove a sua). Os postos de coleta de sangue são, em geral, poucos e afastados do trabalho ou da moradia dos possíveis doadores. Altas ocasionais de doações (por ocasião de tragédias ou alistamento militar) não substituem o necessário fluxo contínuo e levam a um excedente momentâneo de sangue que, muitas vezes, acaba desperdiçado.

A doação de reposição (aquela solicitada por ocasião do atendimento de alguém) não é suficiente para suprir o sistema, uma vez que certos tratamentos hemoterápicos requerem grandes quantidades de sangue. Em conseqüência da falta de doadores, muitas vezes operações são adiadas ou, em casos de urgência que necessitem de um tipo sanguíneo menos comum, é necessário recorrer a apelos pelo rádio ou televisão (compare-se esta situação com o que aconteceu em recente acidente ferroviário na França, em que rádios e TVs avisavam a população que $n a ̃ o$ eram precisos doadores, uma vez que o estoque regular dava conta das necessidades para $o$ atendimento dos numerosos feridos).

Hemofílicos sofrem constantemente a falta de hemoderivados, como revelam depoimentos prestados durante o Tribunal Henfil, em São Paulo, em 20/5/88. Lucia Lara, viúva do proprio Henfil, afirmava naquela ocasião: "Durante dez anos acompanhei o que significa correr atrás de sangue. Corre-se o risco de morrer de Aids, corre-se o risco de morrer de falta de sangue. Muitas vezes eu ligava para todo o Brasil atrás de crioprecipitado e não achava, tinha que sair pela imprensa anunciando. Corre-se o risco de morrer por não ter dinheiro para pagar os medicamentos, que são muito caros porque não existem no país. O crioprecipitado é taxado como produto supérfluo." (Crioprecipitado é um produto do sangue, indicado para hemofilia.)

9 Um trabalho excelente procurou organizar e transmitir os poucos dados disponíveis: Sérgio Henrique Ferreira (editor convidado), "O Brasil precisa de sangue", Ciência Hoje (9) 52, abril 1989:44-61. 
Muitos hemocentros públicos operam abaixo de sua capacidade por falta de doadores. Este quadro não se tornou menos agudo depois da entrada do vírus HIV no Brasil; ao contrário, a disseminação do medo de contaminação na própria doação de sangue agravou-se com a Aids, afastando muitos doadores potenciais. Este medo aparentemente absurdo (uma vez que os bancos de sangue regulares usam material descartável para coleta) em parte se justifica quando se consideram as condições precárias de alguns bancos, em especial daqueles que realizam coletas por plasmaferese. ${ }^{10}$ Em São Paulo, em 1984, foi fechado o Instituto de Hematologia de Guarulhos, que, para agilizar o processo de coleta por plasmaferese, injetava no doador hemácias já separadas do doador anterior, tendo também assim malária a cinco doadores.

Outro problema importante é o alto índice de doenças entre os já insuficientes candidatos a doadores. Isto leva à eliminação de porcentagem significativa de candidatos, se a seleção for bem feita (no Hemocentro de Campinas, entre $10 \%$ e $12 \%$ dos que se oferecem para doar são recusados na triagem clínica), ou, o que é bastante oneroso, à recusa de uma parcela significativa do sangue já coletado, acarretando despesas inúteis com o material de coleta, bolsas plásticas, testes, pessoal etc. (No Instituto Estadual de Hematologia Arthur de Siqueira Cavalcanti - IEHASC - , no Rio de Janeiro, o índice de perda chega a 12\%). A elevada soropositividade entre doadores aumenta também o risco de incidência de doenças transfusionais, uma vez que os testes realizados para deteç̧ão dos agentes de tais doenças nunca apresentam margem de segurança de $100 \%$. Esta situação aponta, por um lado, para a má saúde da população brasileira, já que malária e Chagas são endêmicas em grandes áreas do território nacional. Por outro lado, o problema se liga ao fato paradoxal de ser a população mais pobre a que mais doa sangue no Brasil. Sofrendo de más condições de alimentação, moradia e assistência médica, ela geralmente apresenta uma elevada morbidade por doenças infecciosas. "No Brasil, as classes médias e alta nunca doam sangue", afirma Mariza Ribeiro, diretora do hemocentro de Brasília, em entrevista a Ciência Hoje. "Justamente nelas se localizam os indivíduos mais sadios, teoricamente mais aptos a doar." ${ }^{11}$ dos problemas da doação, os hemoterapeutas e os movimentos formados no período pós-Aids

10 Plasmaferese é um procedimento pelo qual se extrai sangue de um doador, impede-se sua coagulação e separam-se seus componentes. Como parte deste processo, as hemácias que foram separadas são devolvidas ao doador por via intravenosa. Consulte-se Toma, fraccionamento, inspección de la calidad y usos de la sangre y de los productos sanguíneos. Genebra: Organização Mundial de Saúde, 1982, p.10.

11 Ver nota 9. 
denunciam problemas graves referentes ao processo hemoterápico. O sangue é coletado em bolsas plásticas que deveriam garantir maior segurança quanto à assepsia do que os frascos de vidro anteriormente utilizados. As bolsas devem ser feitas de material atóxico e sob condições rígidas de higiene. Porém, as fábricas nacionais que passaram a abastecer o mercado interno funcionavam em condições precaríssimas, o que deu origem a uma série de problemas transfusionais, por contaminação bacteriana ou química (com o próprio material das bolsas). A questão culminou com a interdição, em outubro de 1986, de todas as fábricas de bolsas plásticas, o que gerou outro problema: a escassez de bolsas (fato que, nos últimos tempos, não raro impediu fosse colhido o sangue dos doadores que se apresentavam em alguns serviços). Atualmente, embora tenha sido reiniciada em algumas fábricas, a produção está muito abaixo das necessidades do mercado interno, o que leva à importação de boa parte das bolsas necessárias. A importação, por sua vez, é dificultada por trâmites burocráticos, o que muitas vezes leva os serviços a pedir "empréstimos" de bolsas a outros.

Um problema paradoxal, se considerada a dificuldade de obtenção de doadores de sangue, é a indicação de sangue sem necessidade. Isto se liga, por um lado, à falta de conhecimentos em hemoterapia por parte da maioria dos médicos brasileiros, uma vez que esta disciplina não faz parte do currículo regular das universidades. A especialidade é oferecida em pouquíssimas escolas. ${ }^{12}$ Quando o Instituto Nacional do Câncer, no Rio de Janeiro, estabeleceu um controle das prescrições, constatou no primeiro mês que $45 \%$ das transfusões eram mal indicadas (Guido de Azevedo). ${ }^{13}$ As transfusões desnecessárias ligam-se ao despreparo de muitos médicos para lidar com o sangue como recurso terapêutico. Ainda Guido de Azevedo: “A transfusão, com o sangue já anticoagulado em frasco de vidro, era uma espécie de panacéia. Servia para revigorar, vitalizar. E não havia preocupação com problemas relacionados à transmissão de doenças." Segundo Crescêncio Antunes da Silveira, médico hematologista, "muito sangue é prescrito sem necessidade. É preciso uma discussão da prática médica: quando se deve usar o produto. Há uma prática condicionada dos médicos em prescrever certas terapêuticas. (...) O cirurgião sai da cirurgia e diz: passa um sanguinho nele. Não há uma reflexão (...) se

$12 \mathrm{Na}$ proposta de regulamentação do texto constitucional (artigo 199), um grupo de profissionais de hemoterapia sugere o seguinte: "Torna-se obrigatória a inclusão da disciplina de Hemoterapia nos cursos de graduação, formação técnica e básica das categorias profissionais envolvidas com a prática hemoterápica". Ver nota 9.

13 Entrevista ao Cebrap em 1/7/88. 
precisa ou não."14 José Airamar Padilha, diretor da Vigilância Sanitária da Secretaria Estadual de Saúde do Rio de Janeiro (1987/88): “A gente sabe de alguns casos de pessoas que pegaram Aids numa prescrição desnecessária de sangue". ${ }^{15}$ Outra questão ligada ao sangue prescrito sem necessidade, no âmbito do atendimento privado, é a do "teatro" proporcionado pelo ato transfusional, que serve de pretexto para aumentar a conta apresentada pelo médico ou hospital.

Aponta-se outro problema que vem agravar a escassez do sangue: no Brasil, a maior parte do sangue é transfundido integralmente. Na moderna hemoterapia, no entanto, busca-se estocar o sangue fracionado em seus vários componentes - o que aumenta o prazo de conservação - e transfundir apenas o elemento necessário a cada caso (hemácias, plaquetas etc). "O desperdício no Brasil é menos devido ao sangue vencido do que ao fato de que aqui se emprega muito mais sangue total do que fracionado, causando por exemplo escassez de plaquetas, o que não haveria se o sangue fosse fracionado" (Cármino de Souza). ${ }^{16}$ Isto se liga em parte à falta de aparelhagem técnica para o fracionamento do sangue e ao desinteresse de grande parte dos bancos de sangue de aperfeiçoarem seus serviços. Mas a causa principal desta situação é a falta de pessoal especializado, de nível médico e técnico.

Estima-se que no Brasil, há hoje, cerca de 600 hemoterapeutas em atividade, número insuficiente para fazer face às necessidades atuais. A formação do pessoal técnico laboratorial é a mais precária possível, adquirida na maioria das vezes na prática, o que faz com que o profissional siga apenas rotinas de trabalho e desconheça sua real (im)propriedade. Isto constitui uma grave ameaça à segurança dos testes e procedimentos realizados. A falta de pessoal especializado impede que equipamentos sofisticados possam ser utilizados: "O problema crítico no setor é a falta de recursos humanos. Não adianta ter o material se não se tem quem saiba usá-lo. Só se encontra pessoal preparado nos grandes bancos de sangue privados. No Estado, não há" (Paulo Machado, diretor do Hemocentro de Botucatu). ${ }^{17}$ Cármino de Souza associa a grande escassez de profissionais à inexistência de cursos de hemoterapia nas faculdades de medicina, como cadeira obrigatória: "Cada profissional se forma aleatoriamente."18

14 Entrevista ao Cebrap em 27/6/88.

15 Entrevista ao Cebrap em 4/7/88.

16 Entrevista ao Cebrap em 28/3/88.

17 Entrevista ao Cebrap em 15/4/88.

18 Entrevista ao Cebrap em 28/3/88. 


\section{A legislação depois da AIDS}

O controle da transmissão do vírus da Aids através das transfusões de sangue e da aplicação de hemoderivados foi possível desde 1985, quando os testes anti-Aids tornaram-se disponíveis no mercado. O governo federal, porém, relutava em tornar obrigatória sua aplicação, sob as alegações de que o combate àquela doença não era prioridade, em face de tantos outros problemas de saúde, e de que a implantação do teste exigiria a aplicação de grande soma de recursos. Na ausência de obrigação legal, apenas uma minoria de serviços mais preocupados com a qualidade do sangue passaram, por conta própria, a aplicar o teste. A grande maioria continuou a não aplicá-lo, uma vez que tal procedimento aumentaria os custos e diminuiria os lucros obtidos com a coleta e a venda do sangue.

Entretanto, havia um clamor da opinião pública por mudanças. Veiculadas pela imprensa, as pressões de organismos internacionais (oficiais, como a Organização Mundial de Saúde, e não governamentais, como a organização dos Médicos Sem Fronteira) faziam-se sentir no Brasil, fortalecendo as iniciativas de associacões brasileiras preocupadas com a qualidade do sangue. Para sanar a omissão federal, a Secretaria da Saúde do Estado de São Paulo tornou obrigatória, em junho de 1986, a realização do teste para deteç̧ão do anticorpo da Aids em todo o sangue utilizado em atividades hemoterápicas no Estado. No resto do país, porém, a aplicação do teste continuava facultativa. Só em janeiro de 1988, dias depois da morte de Henfil (causada por Aids transfusional), foi estabelecida a obrigatoriedade do teste, através da lei 7649, de 25/1/1988. É interessante notar, no espírito da antiga ficção que caracteriza a legislação sanitária do país, que a lei estabelecia a obrigatoriedade de uma série de procedimentos já obrigatórios anteriormente, como o cadastramento de doadores e a realização de provas laboratoriais para hepatite $B$, sífilis e doença de Chagas. Em que pese a fragilidade da obrigatoriedade legal, a lei se destaca por apresentar algumas inovações importantes, atribuindo especificamente às Secretarias Estaduais de Saúde a fiscalização das medidas e determinações, e estabelecendo punições pelo seu descumprimento. A lei, cuja regulamentação estava prevista para um prazo de 180 dias, foi regulamentada já em 11 de fevereiro, pelo decreto 95.721 (Diário Oficial de 12/2/88), o que demonstra a preocupação e a urgência com que foi tratada a questão.

$\mathrm{Na}$ esteira das repercussões que se seguiram à morte de Henfil e de tantos outros por causa da contaminação pós-transfusional, elaborou-se um projeto de lei batizado de "lei Henfil" (que alguns chamam de "lei Saulo Ramos", um de seus autorcs), cncaminhado pelo próprio Executivo Federal ao Congresso. 
Nele, criavam-se punições para a contaminação transfusional. O projeto de lei teve o dom de desagradar gregos e troianos. Parecendo querer redimir omissões passadas com rigor futuro, culpabilizava doadores contaminados e responsabilizava os órgãos e profissionais hemoterápicos pela reparação de danos causados pela utilização de sangue e hemoderivados "independentemente de culpa". Ao mesmo tempo, era omisso em pontos fundamentais, como em não definir o que se entendia por "atividades hemoterápicas" e não discutir a questão da doação remunerada (no Brasil, uma prática aviltante e sem controle legal). Agregava medidas polêmicas, como tornar compulsório o teste anti-Aids a todos os detidos em estabelecimentos penais. Na verdade, persiste um problema crônico para a legislação no setor: se sua ausência permitia que os abusos não fossem ilegais (como não era ilegal, antes de 1988, transmitir Aids pelo sangue), a presença das leis sem a fiscalização necessária ao seu cumprimento a torna inócua, e muitas vezes a mesma medida é reafirmada em vão por leis sucessivas, como acontece para os testes sorológicos.

$\mathrm{Na}$ Constituinte, a questão do sangue mereceu um parágrafo especial dentro do capítulo da Saúde. Foi um tema polêmico, tratado em votação separada por causa de sérias divergências entre as correntes do Congresso denominadas "progressista" e "conservadora". A proibição da comercialização de sangue e seus derivados acabou sendo aprovada por 313 votos contra $127 \mathrm{e}$ 37 abstenções (Proposta 9, maio/junho 88). O sangue representava, para os que defendiam a proibição da comercialização, a defesa dos ideais da Reforma Sanitária e dos direitos da cidadania. Para os que eram contra a proibição, tida como essencial para estabelecer um controle efetivo do sangue no Brasil, o parágrafo significaria o primeiro passo para a estatização do setor saúde, cerceando os direitos da livre empresa e promovendo o caos na saúde do Brasil, uma vez que, segundo se argumentava, o governo seria incapaz de organizar a atividade hemoterápica e garantir bons serviços.

\section{A politização da questão - as instituições e o sangue no Brasil}

A atenção despertada pelo problema do sangue conduziu à cena pública uma série de instituições, governamentais e civis. Órgãos públicos antigos, cuja atuação costumava ficar na penumbra, passam à primeira página dos jornais, como as divisões de vigilância sanitária das Secretarias Estaduais de Saúde. Ao lado de associações civis que tradicionalmente se dedicavam ao problema do sangue (como a Associação Brasileira de Doadores Voluntários de Sangue, a Associação Brasileira dos Hemofílicos etc), surgem novas organizações preocupadas precipuamente com a $\Lambda$ ids, como a Associação Brasileira Interdisci- 
plinar de Aids (ABIA) e o Grupo de Apoio à Prevenção à Aids (Gapa), que se mostram bastante críticas com relação à qualidade do sangue e à ausência ou ineficácia das políticas governamentais. Outra organização, o Comitê Pacto de Sangue, é criada justamente em função dos problemas da atividade hemoterápica no país.

A questão do sangue ocupará espaço em instituições públicas de âmbito maior, como o Ministério da Saúde e a Procuradoria Geral de Justiça, e terá mesmo, como já assinalamos, um destaque significativo nas deliberações da Assembléia Constituinte. Entidades médicas como sindicatos, conselhos regionais de medicina e a Associação Médica Brasileira também se pronunciaram quanto ao sangue.

Os fatos centrais que mobilizaram as discussões, pronunciamentos e iniciativas foram, por um lado, a constatação de índices crescentes de Aids transfusional, com novos casos e escândalos apresentados cotidianamente nos jornais e, por outro, as discussões em torno da proibição da comercialização do sangue na Constituinte.

Estas instituições, algumas divergindo abertamente entre si quanto a propostas e posições, promovem e protagonizam eventos significativos para se compreender com que espírito a questão do sangue vem sendo tratada no Brasil. É o caso das votações da Saúde na Constituinte, em que o sangue foi discutido em separado, o Fórum Estadual do Sangue, no Rio de Janeiro, e o Tribunal Henfil em São Paulo.

Em eventos desta natureza se evidenciou, com nitidez, o que denominamos de "politização" da questão do sangue, motivada pelo aparecimento da Aids pós-transfusional. Seguiu-se um intenso debate político que produziu um conjunto variado de efeitos, alguns extremamente positivos, outros de natureza ambígua, senão negativa, sobre o modo pelo qual a atividade hemoterápica foi considerada. Entre os primeiros, destacam-se as pressões para o controle e disciplinamento das atividades com base em sua necessária e completa reordenação. Entre os últimos, a tendência a considerar a questão do sangue como "questão de polícia" até os dias de hoje, sem se atentar para a diversidade dos serviços hemoterápicos e o ritmo acelerado de mudanças em algumas regiões.

Observar como cada instituição se pronuncia quanto ao sangue e como encara seu papel é fundamental para investigar os vários aspectos do problema hemoterápico brasileiro, arrolando confrontos e alianças que se traduzem em posições muitas vezes transitórias, mas que permitem distinguir certas tendências gerais. 


\section{a. A Sociedade Civil: Gapa, Abia e Comitê Pacto de Sangue}

O Gapa e a Abia são exemplos de organizações criadas em decorrência dos problemas surgidos a partir da disseminação da Aids no país e das questões colocadas para seu combate. Entidades não governamentais, frisam sempre sua autonomia e independência. Preocupadas em denunciar o descaso do governo com a Aids (e com a saúde pública e a população em geral), elas consideram o sangue como uma prova flagrante e criminosa deste desinteresse. Embora se apóiem mutuamente e possam trabalhar em conjunto, cada entidade mantém certa autonomia. O que embasa esta ênfase na autonomia organizacional é justamente a filosofia de atuação de tais entidades, que é explorar ao máximo a capacidade de organização da sociedade civil em torno de interesses comuns e sem interferência de governos ou partidos. Esta independência é, justamente, a garantia de poder, com toda liberdade, cobrar politicamente das autoridades a elaboração e execução de programas ligados à Aids e ao sangue.

O Gapa revela a postura política destas novas organizações ligadas à Aids. A criação do Grupo de Apoio à Prevenção à Aids nasceu da convicção de que somente com a união dos esforços de grupos civis e das instituições públicas, a exemplo do que vem ocorrendo na Europa e nos Estados Unidos, "seria possível obter algum resultado na luta por um tratamento adequado por parte do Estado à questão da Aids, garantindo os interesses da comunidade" (Editorial, Previna-se 1, fevereiro de 1988-6́rgão oficial do Gapa). Criado em São Paulo em 1985 (e contando hoje com grupos no Rio de Janeiro e em Minas Gerais), a partir das palestras mensais promovidas então pela Secretaria de Saúde do Estado de São Paulo, é "aberto a todas as pessoas, independentemente de suas posições sociais, político-partidárias, ideológicas, religiosas, profissionais ou orientação sexual. Entidade civil sem fins lucrativos, o Gapa está envolvido com a promoção de palestras, (...) divulgação de formas de prevenção, (...) promoção de eventos para levantar fundos necessários às campanhas e atendimento a pedidos de esclarecimento e informações. O auxílio material e psicológico aos pacientes carentes e a seus familiares é outra grande linha de ação do trabalho realizado pelo GAPA". (ibid.)

A questão do sangue merece destaque nas atividades do Grupo. $\mathrm{Na}$ publicação Previna-se 1, Paulo Cesar Bonfim (presidente do Gapa e técnico ligado ao sangue) dedica um artigo ao problema do sangue, cuja tônica é a denúncia de omissões, não só governamentais, mas da própria sociedade: "desde 1985 o Gapa vem denunciando que um dos problemas mais graves de Aids no Brasil refere-se à situação em que se encontram os bancos de sangue estatais. privados. hem como aqueles clandestinos.(...) Estabcleccr decretos, 
portarias e leis de nada adianta, se não houver uma atuação de constante vigilância e conscientização (...). Não são suficientes batidas repentinas, multas e repressões. São necessárias medidas eficazes que possam estruturar um serviço de saúde de boa qualidade, ou seja, é fundamental que o governo tenha uma política transparente a esse respeito no que tange não só a seus deveres e direitos, mas também aos dos cidadãos e instituições privadas que lidam com a questão da saúde pública." E conclui: "É preciso lutar juntos para que um dia possamos ter um serviço de saúde pública com condições mínimas de qualidade. Cabe a cada um de nós dar a sua contribuição, controlando, fiscalizando, denunciando e, por que não, elogiando e incentivando quando for merecido."(Previna-se 1, de 1988) Ou seja, cabe ao governo fiscalizar o sangue, mas cabe a cada um cobrar do governo. Não fazê-lo é omissão.

A Abia define-se, em seu folheto de apresentação, como uma "organização não governamental, apartidária e sem fins lucrativos". Foi fundada em 21 de dezembro de 1986 "em busca de uma resposta aos múltiplos problemas causados pela epidemia da Aids em um país como o Brasil". Congrega "cientistas e profissionais de todas as áreas do conhecimento, assim como representantes de todos os segmentos da sociedade. Tenta desenvolver uma abordagem multidisciplinar das questões colocadas pela Aids". Entre suas metas está "acompanhar e avaliar as iniciativas e políticas governamentais com respeito à Aids. Este é um trabalho apartidário fundamental, se consideramos a histórica negligência da saúde pública no Brasil. Somente através da vigilância permanente e da pressão conjunta a sociedade brasileira poderá reivindicar seu direito à saúde, forçando o Estado a assumir a responsabilidade nesta área e produzir e divulgar informações de qualidade sobre a prevenção e controle da Aids."

É constante esta postura de cobrança civil contra o descaso público, bem como a reivindicação de que a sociedade tem o direito de opinar e influir, solidariamente, nas políticas públicas. "É espantoso que o governo ainda não tenha criado condições de uma interação com entidades e organizações não governamentais que têm feito um eficiente trabalho no sentido da informação e da prevenção." (Abia, Boletim 2, abril 88). No tocante ao sangue, as propostas de participação civil e de cobrança às autoridades governamentais são igualmente explícitas. A Abia conclama as vítimas de doenças transfusionais a processar o banco de sangue, hospital ou clínica onde a transfusão se realizou, prática ainda pouco comum no Brasil. "Só as autoridades governamentais podem obrigar e garantir que todos os bancos de sangue e laboratórios façam os testes e selecionem o sangue e os derivados que serão utilizados para salvar outras vidas F́ prortanto, um direito o um dovor do cada cidauãu exigiı UU 
governo solução rápida e eficiente para o controle do sangue no Brasil." (Sangue, direito à vida, folheto informativo da Abia).

A postura independente permite que essas organizações participem das inciativas governamentais, apoiando o que julgam pertinente, cobrando medidas e criticando omissões e posturas com que não concordam, identificando e apoiando planos, posições e pessoas de órgãos públicos com quem partilham interesses. $\mathrm{O}$ trabalho é de apoio ao que consideram correto, combate aos programas julgados equivocados e denúncia e cobrança das omissões.

Como decorrência desta participação ativa da sociedade civil diante das iniciativas governamentais, em 19 de abril de 1988 foi criado, no Rio de Janeiro, o Comitê Pacto de Sangue. Mais do que uma instituição, ele se define como uma iniciativa. Diz Sílvia Ramos: "o comitê é um conjunto de entidades e empresas preocupadas com o sangue. Justamente porque a gente não quer formalizar e funciona cada hora em um lugar, cada reunião é em um lugar. O Comitê não é uma instituição formal que funcione vinte e quatro horas por dia, ele funciona em relação a atividades. A primeira foi apresentar essa iniciativa pioneira de responsabilizar a União (...). Inicialmente a idéia do Comitê Pacto de Sangue é oferecer apoio jurídico para as pessoas que queiram abrir um processo contra a União, de responsabilidade civil, ou em processos de responsabilidade criminal contra bancos de sangue, hospitais e clínicas onde foram contaminados. O comitê é formado por várias entidades. Além da Abia, o Sindicato dos Médicos do RJ, o Cremerj, a Fiocruz, o Movimento Nacional de Defesa dos Direitos Humanos, a Associação de Doentes Renais Crônicos do RJ, a Associação Brasileira de Talassêmicos, a OAB, a Associação dos Juristas das Causas Populares, a Associação Brasileira de Odontologia, o Gapa (...). Uma série de entidades preocupadas com a qualidade do sangue e algumas pessoas." (Ver nota 4) Através deste depoimento, evidencia-se o caráter político-pedagógico das linhas de ação do Comitê e de instituições civis como a Abia.

As relações dessas organizações com o governo variam caso a caso, do embate frontal ao apoio decidido. Tome-se o exemplo da relação entre a Abia e a Secretaria Estadual de Saúde do Rio de Janeiro. Segundo Sílvia Ramos (ver nota 4), em 1988 a Secretaria cumpriu um programa mínimo, "a que se comprometeram conosco", que era de recadastrar os bancos de sangue. "Estão fazendo algumas coisas, o que não chega a mudar a situação calamitosa da Aids no Rio de Janeiro. Mas, pelo menos quanto ao sangue, hoje o nível de controle e preocupação é absolutamente superior ao que era há um ano atrás. É tudo muito lento, há a burocracia, dificuldades, mas alguma coisa está sendo reali7ada. A gente tem com elę uma relą̧ão do apoio público. Apoiv c cubı alļ̧a." 
Processando, denunciando, promovendo iniciativas como o Tribunal Henfil em São Paulo (iniciativa do Gapa e da vereadora Tereza Lajolo, do Partido dos Trabalhadores), reafirmando posições junto à imprensa, acompanhando de perto iniciativas governamentais, participando de comissões (como a que reestudou o projeto da lei conhecida como "lei Henfil"), fazendo lobby no Congresso Nacional, estas entidades vêm marcando presença e mantendo uma postura independente diante das iniciativas governamentais. Lutam para que 0 governo se torne antes de tudo um executor daquilo que é deliberado socialmente.

\section{b. Associação Brasileira de Doadores Voluntários de Sangue}

Fundada nos anos 60, a ABDVS (organizada nos moldes de uma associação beneficente) gira em torno da figura de D. Carlota Osório, sua presidente desde a fundação. A instituição pretende manter-se paradoxalmente "acima da política", por defender uma causa humanitária. Sua atuação é de incentivo à doação voluntária (através de campanhas, concursos de slogans, etc) e de luta contra a doação remunerada e a especulação comercial com o sangue. A ABDVS que apoiou a decisão da Constituinte de proibir a comercialização do sangue e derivados, é a favor da estatização das atividades hemoterápicas - neste particular, sem dúvida, está longe de ser "apolítica". É a organização civil mais antiga no Brasil que se preocupa especificamente com o problema do sangue.

O folheto da ABDVS apresenta a organização desta forma: "A ABDVS é uma entidade filantrópica de utilidade pública, cuja origem vem da Associação do Rio de Janeiro, fundada em 1949. Como Conselho de Ordem Nacional tem a finalidade de implantar, promover, organizar e defender o Voluntariado de Sangue em todo o país. Atua sem ônus para os cofres governamentais pois é dirigida e executada (sic) por voluntários. Propositalmente funciona sem fundos monetários, provando que o Amor ao Próximo pode ser a única força motriz de uma ação eficiente e eficaz em prol da Saúde Pública." A Associação procura despertar uma formação altruística na população, através de campanhas educativas de doação voluntária que "despertam a felicidade, o prazer e a satisfação de, com um pouco de sangue, salvar a vida de alguém que nunca conhecerá - gesto mais nobre de que um homem é capaz". Destaca ainda a importância do sangue para a "segurança nacional", como material crítico e patrimônio da nação, sempre à disposição de quem dele necessitar. 
A atuação da ABDVS é baseada fundamentalmente nos contatos sociais de D. Carlota Osório que, como figura de elite, ${ }^{19}$ transita com desembaraço nos meios políticos. Seu currículo (que acompanha o folheto de apresentação da ABDVS) acumula condecorações, títulos, honrarias e cargos de presidência em associações ligadas à doação voluntária. Das suas principais iniciativas, constam " 27 anos de luta contra a mercantilização de sangue (...), combatendo a máfia do sangue por todos os meios de comunicação, inclusive em âmbito internacional".

D. Carlota Osório denuncia constantemente o contrabando de plasma de países do Terceiro Mundo (entre eles o Brasil) para as indústrias de hemoderivados da Europa e dos Estados Unidos: "Há pouco tempo, em um congresso na Alemanha, o presidente da Cruz Vermelha me pediu (...) que continuasse a denunciar esta saída clandestina de sangue (plasma), porque já estão sendo verificados casos de doença de Chagas na Europa, área que não apresenta registro desta doença." Na entrevista que nos concedeu, ${ }^{20}$ denunciou o que the parece ser uma "conivência" da Cruz Vermelha Brasileira com o contrabando de plasma e a "filantropia de fachada" da Casa do Hemofílico: "No mundo inteiro se aproveitam dos hemofílicos para conseguir sangue que acaba desviado para outros propósitos."

D. Carlota Osório critica algumas sociedades civis, ao comentar, em entrevista, sua ausência ao ato público que criou o Comitê Pacto de Sangue: "Fico meio em dúvida com o ato público da viúva do Henfil, porque eles são muito políticos e querem envolver todo mundo. Todos sabem que eu sou a favor da estatização (dos bancos de sangue), mas eles são a favor da estatização de tudo." (Ver nota 20) Por outro lado, D. Carlota Osório faz críticas à atuação do governo na área hemoterápica. Declara (Tema 10, p. 18): "Os ministros com quem tive contato sempre se mostraram sensibilizados para a questão do controle do sangue, mas não tomavam decisões administrativas que correspondessem a um verdadeiro caminho para a solução do problema do sangue." Propõe, na mesma entrevista, um "tripé de moralização" para a questão do sangue, baseado em 1) construção de serviços oficiais de coleta e distribuição do sangue; 2) grande campanha de conscientização da população, incentivando a doação, e 3) criação de uma lei que regule correta e completamente a questão do sangue, proibindo o lucro, exigindo a mais estrita fiscalização e punindo severamente os desobedientes. Considera que o problema não pode ser resolvido por decreto, "solução costumeira e imediatista", sendo necessários "recur-

19 Viúva de um neto do General Osório, considera que este "até hoje nos abre portas".

20 Entrevista ao Cebrap em 19/4/88. 
sos adequados à integração de todos os setores que lidam com sangue. E, sobretudo, teremos que ver que não é só a rede de hemocentros que viabilizará a solução, mas sim os postos de coleta descentralizados, de maneira que os doadores tenham toda a facilidade possível para se deslocar de sua moradia ao posto de coleta."

A preocupação de manter-se "acima da política" torna a ABDVS manifestamente diferente das organizações civis criadas na década de 80 , que consideram a questão do sangue no Brasil um problema eminentemente político-econômico. Entretanto, a atitude supostamente apolítica de sua direção poderia ser entendida mais corretamente como uma recusa à política partidária que caracteriza algumas correntes do movimento sanitarista. Note-se que organizações como a Abia também se situam acima de interesses partidários e, neste particular, não se distanciariam, na prática, da Associação liderada por Carlota Osório.

\section{c. O setor privado}

A seção anterior procurou discutir os setores da sociedade civil que se organizaram em entidades, organizações e movimentos de defesa dos interesses da população contra a precariedade dos serviços hemoterápicos no Brasil, em especial em relação a seu impacto sobre as chamadas doenças pós-transfusionais. A seguir se analisa o setor da sociedade civil organizado com fins lucrativos, em empresas de comercialização do sangue e seus derivados.

A análise da produção privada que visa a suprir a demanda hospitalar por sangue não tratará do submundo do tráfico de sangue, que tem sido alvo das mais duras e pertinentes críticas da imprensa e das entidades civis que analisamos, e que, apesar da fiscalização crescente, parece ainda resistir em alguns "bolsões" no Sudeste. Esta é, sem dúvida, uma questão de polícia, e não apenas de polícia sanitária.

Assinale-se inicialmente que o setor produtivo está marcado por uma grande diversidade de serviços, nem todos com fins lucrativos. Há um grupo de antigos hemoterapeutas, ligados ao desenvolvimento do Banco de Sangue do Hospital do Servidor Público em São Paulo. Mas a quase-totalidade do setor relaciona-se à produção com lucro. Há outro grupo de antigos profissionais, ligados aos bancos de sangue de hospitais privados, como o Sírio Libanês e o Albert Einstein, em São Paulo, considerados serviços hemoterápicos de primeira linha. De outro lado, há um grupo de empresários ligados a pequenos bancos de qualidade variável. 
Mas esta diversidade é muitas vezes desconsiderada em favor de um conjunto mais ou menos generalizado de acusações contra o setor privado. A primeira grande acusação recai sobre a impossibilidade de fazer coincidir lucro e interesses da população. A segunda grande acusação, relacionada sem dúvida à questão do lucro, mas que foi a peça de resistência durante os debates na Constituinte, dirige-se à baixa qualidade dos serviços prestados pela hemoterapia privada. Reporta-se com razão ao drama brutal dos hemofílicos, $85 \%$ dos quais estariam hoje contaminados pelo vírus da Aids em função de transfusões sanguíneas.

Se lucro e reais interesses da população são ou não compatíveis é um debate que não cabe nos propósitos do presente trabalho. Entretanto, cabe certamente sublinhar que o lucro ligado ao correto exercício profissional, como ocorre em hospitais como o Sírio Libanês ou o Santa Catarina em São Paulo, não é obtido 'da mesma maneira que o lucro de bancos que visam apenas ao ganho financeiro, como muitos da Baixada Fluminense.

Os profissionais do setor privado, ao analisarem o setor hemoterápico, costumam apontar para duas ordens de problemas: aqueles ligados diretamente à operação dos bancos de sangue e aqueles associados ao modelo hemoterápico proposto a partir do Pró-Sangue.

Com relação ao primeiro grupo de problemas, o médico Silvano Wendel Neto, do Hospital Sírio Libanês, ${ }^{21}$ alerta para o fato de que até hoje nem todos os bancos de sangue, espalhados pelo território nacional, aplicam os quatro testes sorológicos obrigatórios. Outro problema reside na qualidade dos insumos usados pelos bancos de sangue. Este é o caso, por exemplo, dos filtros de transfusão disponíveis no mercado. Um deles, que custava na época da entrevista $\mathrm{Cz} \$ 3,00$, obedece a padrões internacionais de qualidade e é consumido quase exclusivamente pela rede de bancos de sangue de primeira linha. $\mathrm{O}$ outro, que custava $\mathrm{Cz} \$ 0,45$, é usado na rede do Inamps e, embora aprovado pela Dimed, apresenta características indesejáveis, como o tubo rígido que permite a entrada de ar no filtro; este tubo tende a aumentar a chance de um paciente ter, por exemplo, uma complicação pulmonar pós-operatória.

Há ainda a questão da seleção dos doadores, nem sempre realizada com suficiente rigor, embora seja absolutamente necessária. Há doenças, como a hepatite não-A não-B, para as quais não existem marcadores sorológicos e cuja incidência é maior em populações que vivem em regiões onde o saneamento é precário. A contaminação dos hemofílicos, sustentam alguns hemoterapeutas,

21 Silvano Wendel Neto. Diretor do Banco de Sangue do Hospital Sírio Libanês, Secretário da Sociedade Brasileira de Hematologia e Hemoterapia. Entrevista concedida ao Cebrap em 2/3/89. 
tem origem em problemas complexos de produção em grande escala de "concentrado de fator 8", em frascos liofilizados. Diz Geraldo de Souza Patto, do Hospital Santa Catarina: "O produto industrial é um pool de (alguns milhares) de litros de plasma que dão origem a uma partida imensa de frascos liofilizados com fator 8 concentrado. Em um lote contaminado pode-se imaginar o poder de contaminação." ${ }^{22}$ Remando contra a corrente das críticas aos bancos de sangue, Souza Patto lembra que o crioprecipitado úmido, preparado em bancos de sangue e obtido de doadores individuais, não pode ser considerado responsável pela contaminação dos hemofílicos. De todo modo, no caso da escala industrial ou da produção não liofilizada, permanece a questão crítica da seleção dos doadores.

Para estes hemoterapeutas, a culpa pelos problemas do meio cabe à autoridade governamental, que nunca teria estabelecido uma política firme para o setor, ou ao menos levado adiante uma fiscalização efetiva. Entretanto, quando se fala dos programas oficiais para a área de sangue - tentativas de estabelecer uma "política firme" -, os hemoterapeutas entrevistados tornam-se mais críticos. Nesse sentido, eles estão muito mais empenhados em apontar as deficiências do modelo, do que propriamente em defender um projeto alternativo capaz de solucionar o problema da oferta de sangue para o conjunto da população.

A avaliação que os hemoterapeutas entrevistados fazem do Pro-Sangue começa com uma crítica unânime à centralização dos serviços de coleta, processamento e transfusão.Para alguns, este problema seria minimizado se a coleta e o processamento ficassem centralizados, mas mantida a transfusão intra-hospitalar. Para outros, no entanto, o banco de sangue, englobando coleta, processamento e transfusão, deve ser sempre intra-hospitalar, já que a utilização de sangue se dá sobretudo em serviços razoavelmente complexos e capazes de manter bancos de sangue de qualidade. Neste caso apenas a sorologia seria centralizada, porque reduz sensivelmente os custos. Para os hemoterapeutas que defendem esta última proposta, a própria mudança que vem ocorrendo no ideal de doação dificultaria a expansão de serviços centralizados. Como se sabe, o princípio de operação destes serviços é o desconhecimento mútuo entre doador e receptor. Hoje, entretanto, estaria crescendo o número de receptores que querem conhecer a origem do sangue que receberão. Esta situação estaria levando ao crescimento do número de transfusões autólogas e casadas, ${ }^{23}$ nesses

22 Geraldo de Souza Patto. Diretor do Banco de Sangue do Hospital Santa Catarina, fundador e ex-sócio da Bio Test. Entrevista concedida ao Cebrap em 30/4/89.

23 Nas transfusões casadas o receptor trás o doador; na autóloga, ele recebe seu próprio sangue, previamente coletado e estocado. 
casos, se a coleta e o processamento fossem feitos no hemocentro e depois o sangue enviado aos hospitais para transfusão, haveria o risco de altos índices de erro administrativo, com a troca do material coletado.

Outro problema creditado ao Pró-Sangue é que este estaria se propondo a reeditar o modelo francês sem, no entanto, atentar a certas especificidades desse modelo, como a de que na França (e nos EUA) os hemocentros são gerenciados comunitariamente, sendo mínima a interferência do Estado. Sublinham ainda $o$ fato de que países do Primeiro Mundo mantiveram bancos de sangue hospitalares. A crítica se estende ao projeto da indústria de hemoderivados que, nesses países, é privada, ao contrário daquilo que se planeja para o Brasil, a partir da nova Constituição.

Quanto às possibilidades de acomodação do setor privado a um sistema baseado em centrais públicas de processamento de sangue (que mantivesse a transfusão ligada aos hospitais), o principal argumento favorável seria a economia gerada por um sistema que operasse em grande escala. Os argumentos desfavoráveis, entretanto, são muitos e estão ligados sobretudo à suposta dificuldade de se manterem, dentro do serviço público brasileiro, padrões de qualidade constantes. Esta dificuldade, argumenta-se, decorreria da instabilidade das políticas governamentais, que a todo momento substituem os quadros de gerenciamento, criando uma indefinição nos objetivos e recursos disponíveis para os diferentes programas.

A estratégia de organização da coleta colocaria outro problema para o entrosamento, pois, enquanto os serviços de primeira linha são extremamente cuidadosos na seleção dos doadores, os hemocentros, ao atenderem populações que vivem em diferentes condições de saneamento (veja-se o caso da hepatite, descrito anteriormente), tenderiam a "misturar" sangue coletado com diferentes graus de risco, expondo a população a danos desnecessários.

Resta saber sob que condições estes hemoterapeutas consideram viável o projeto dos hemocentros. Para alguns, "não é possível que somente uma faixa da população com poder aquisitivo tenha direito a tratamento". Os hemocentros deveriam ser incentivados "no âmbito destas populações e das regiões do Brasil onde a ação federal se faz absolutamente necessária". ${ }^{24}$ Apesar de todos os problemas apontados, os hemocentros representariam um progresso real na qualidade dos serviços hemoterápicos que essas populações vinham recebendo.

24 Jacob Rosemblit, membro do corpo clínico do Hospital Israelita Albert Einstein, Diretor do Banco de Sangue do Hospital do Servidor Público de São Paulo de 1961 a 1986 e ex-presidente da Sociedade Brasileira de Hematologia e Hemoterapia. Entrevista concedida ao Cebrap em 28/3/89. 
Para outros, como o hemoterapeuta Nelson Hammerslack, do Hospital Albert Einstein em São Paulo, os hemocentros deveriam se constituir em suporte ao ensino técnico e universitário, centro de pesquisa, retaguarda dos hospitais ${ }^{25} \mathrm{e}$ orgão de fiscalização. ${ }^{26}$ Sua atividade hemoterápica se restringiria ao atendimento, por exemplo, de um hospital universitário. Nesta visão, a capacidade dos hemocentros, hoje instalados, seria mais bem aproveitada como suporte para a formação de hemoterapeutas e de uma fiscalização competente, fatores capazes de sustentar um desenvolvimento futuro assentado na competência técnica.

Quanto ao sistema como um todo, o Estado deveria gerir seus hospitais, ficando reservado à iniciativa privada o direito de encontrar seu próprio modelo de funcionamento. A qualidade dos serviços seria garantida pelo profissionalismo dos hemoterapeutas e por um sistema de fiscalização efetivo.

\section{As instituições médicas}

A colocação do problema do sangue no Brasil como uma questão de saúde pública e a discussão a respeito da proibição da comercialização do sangue e hemoderivados (o que, para alguns setores, significaria uma estatização das atividades hemoterápicas) fizeram com que as entidades médicas debatessem a questão, fazendo pronunciamentos oficiais ou promovendo discussões em eventos como o Fórum Estadual de Sangue no Rio de Janeiro.

A questão do sangue surge, para as associações médicas, em um momento de grande discussão dos rumos da medicina do Brasil. A crise geral da rede pública de saúde, a crescente privatização dos serviços de saúde, com o surgimento de convênios e assalariamento de médicos, os alarmantes índices de endemias, as críticas ao modelo curativo-hospitalar, tudo isso é levantado no momento em que se discute (e tenta-se implantar) uma reforma sanitária no país, que acarretaria uma reestruturação do sistema de saúde como um todo e uma guinada nos propósitos da saúde pública no país.

As discussões e avaliações da questão do sangue, por parte das várias associações médicas, guardam sempre uma ligação estreita com o debate sobre a saúde como um todo. Note-se que é impossível separar o debate que ocorre no interior da corporação médica e que ocorre no plano das instituições

25 Um exemplo desta situação seria o caso em que o banco de sangue,ao necessitar de uma hemácia rara,recorreria ao hemocentro para obtê-la.

26 Nelson Hamerschlak é hemoterapeuta do Banco de Sangue Alberto Einstein e presidente do Centro de Hematologia de São Paulo. Entrevista concedida ao Cebrap em 30/4/89. 
governamentais, pois são freqüentemente os mesmos atores que falam. As posições médicas estão representadas em todos os níveis da administração pública. Cada órgão governamental é "ocupado" pelos partidários desta ou daquela posição, o que leva a um atrito político constante, com uma grande rotatividade de cargos e frequentes mudanças nas políticas de cada órgão. $\mathrm{O}$ conflito ocorre dentro de instituições como o Ministério da Saúde ou secretarias estaduais de saúde, e entre as instituições governamentais (Fiocruz X Ministério da Saúde, Secretarias de Saúde X Inamps). Nenhuma corrente é suficientemente forte para imprimir um rumo firme à política pública de saúde, e os planos traçados são interrompidos e modificados ao sabor das oscilações das forças políticas. Tome-se o exemplo de certas correntes ligadas ao modelo privatizado de saúde, que se fazem representar na própria máquina governamental, fazendo com que se reforce, através do Inamps, o modelo de contratação de serviços de saúde e impedindo muitas vezes planos e medidas contrários a seus interesses. $\mathrm{O}$ caso de sangue obtido gratuitamente de doadores por entidades falsamente filantrópicas, e em seguida comercializado para a Previdência Social, é um exemplo de distorção em favor de alguns setores da iniciativa privada. ${ }^{27}$

$\mathrm{O}$ que todos os grupos médicos têm claro é a importância da política governamental para definir o perfil do modelo de saúde brasileiro e, conseqüentemente, da medicina entre nós. As decisões governamentais afetam os médicos como categoria, podendo alterar seu estatuto profissional. Os médicos, corporativamente, reagem contra as medidas que consideram restritivas ao seu livre exercício profissional. Todas estas discussões afloram, contextualizadas, quando as instituições médicas debatem o problema do sangue. Vamos observar as posições de algumas destas entidades quanto ao sangue e à saúde. Tanto a diversidade das posições quanto os conflitos que dela decorrem estão presentes na análise institucional que se segue. Os casos da Sociedade Brasileira de Hematologia e Hemoterapia e do Sindicato de Médicos do Rio de Janeiro, para citar dois, destacam-se no quadro institucional discutido a seguir.

\section{A Sociedade Brasileira de Hematologia e Hemoterapia}

A SBHH, fundada na década de 1950 , foi, como já se viu, a primeira entidade a congregar especialistas em hematologia e hemoterapia. Até 1980, no entanto, a direção da entidade não se posicionou vigorosamente contra as péssimas condições em que operava o setor hemoterápico. Apenas nessa

27 Ver artigo publicado em Ciência Hoje (nota 9). 
década, em meio à polêmica que se abriu em torno do Pro-Sangue e da Aids, tomou publicamente posição em favor dos seguintes objetivos: defesa do livre exercício profissional e da livre iniciativa na área; extinção da doação remunerada, vista pela Sociedade como a principal causa dos problemas da hemoterapia brasileira; crítica ao Estado brasileiro como executor das políticas de sangue. Dada a pesada máquina estatal, alegava-se que a intervenção estaria fadada ao insucesso, quer pelo alto custo que incorreria, quer pela pouca eficiência com que o Estado tenderia a desempenhar estas funções.

A partir de 1980 a SBHH passou a defender a atuação do Estado apenas como órgão fiscalizador, promotor de pesquisas e gerenciador de incentivos fiscais, e não como agente executivo de uma política nacional de sangue.

Seguindo uma linha de defesa da iniciativa privada no setor hemoterápico, a SBHH empenhou-se contra a proibição da comercialização do sangue votada na Constituinte. Argumentava que a desmontagem do setor privado seria desastrosa. Segundo declarava à imprensa o então presidente da SBHH, Hélio Ramos, "seriam necessárias duas décadas para estatizar esses serviços. Isso seria desastroso para todos os doentes que precisam de sangue para sobreviver." (Veja, 15.6.88) Os médicos sanitaristas sempre avaliaram estas posições como conservadoras. O conflito entre estas perspectivas foi agudo durante o Fórum Estadual de Sangue, promovido pelo Cremerj em março de 1988, no Rio de Janeiro.

A SBHH distribuiu no início dos debates um documento em que questionava o critério de escolha dos conferencistas, que teria alijado os hematologistas da entidade. Durante os debates, Luiz Felipe Moreira Lima, coordenador do Programa Estadual do Sangue e Hemoderivados do Rio de Janeiro, declarava, rebatendo as críticas de que o programa não contava com especialistas na área de hemoterapia: "Eu pessoalmente não quero assessoria da SBHH [para o PROESAH], já que a única sociedade que justificou o comércio do sangue foi a SBHH." A discussão prosseguiu com uma troca de acusações entre o coordenador do programa e o secretário da SBHH, o primeiro acusando o segundo de que a SBHH saíra em defesa de fábricas de bolsas plásticas de péssima qualidade, o segundo retrucando que o primeiro era um dos responsáveis pelo adiamento da obrigatoriedade dos testes anti-Aids, quando trabalhava no Serviço Nacional de Vigilância Sanitária.

Tentando interromper o processo de radicalização das posições - esforço cuja eficácia ainda não ficou demonstrada - , um grupo de jovens hemoterapeutas se reuniu em fins de 1988 para disputar as eleições à diretoria da SBHH. Esse grupo, caracterizado como um grupo "misto", é formado tanto por membros do Gepro da Secretaria de Saúde do Estado de São Paulo (o Grupo Especial 
do Programa de Hematologia e Hemoterapia), como, por exemplo, pelo diretor do Banco de Sangue do Hospital Sírio-Libanês. A chapa venceu as eleições com propostas que tentavam tirar a Sociedade do impasse "público versus privado", através da idéia de que deveria gerenciar os aspectos mais técnicos ligados à especialidade. Para esse grupo, a Associação Americana de Bancos de Sangue é vista como um modelo. Sobre ela diz o secretário da SBHH, Silvano Wendel: "Trata-se de um órgão científico com força para ditar normas que, mesmo não sendo obrigatórias dentro da Vigilância Sanitária americana, são respeitadas dada a força da instituição." 28

Para estes hemoterapeutas, não caberia à SBHH definir uma politíca de sangue. Ela seria, antes, um reduto de especialistas de primeira linha, capazes de carimbar um "selo de garantia" sobre as instituições hemoterápicas, públicas ou privadas. Com isso, estes hemoterapeutas tentam levar adiante a idéia de que, ao lado das opções sobre política hemoterápica, é importante valorizar-se a qualidade dos serviços hemoterápicos. Como se verá a seguir, para outras instituições esta valorização cede lugar, não raro, à primazia do debate sobre política hemoterápica como instância de uma política global de saúde para o País. Neste terreno é difícil o consenso.

\section{O Cremerj}

O Conselho Regional de Medicina do Rio de Janeiro é uma das entidades médicas que mais se tem pronunciado a respeito da questão do sangue no Brasil. Isto se deve, entre outras razões, ${ }^{29}$ ao fato de que o Rio de Janeiro ostenta o mais alto índice de Aids transfusional no Brasil (em 1989, o estado acumulava cerca de $20 \%$ do total de casos) e, além disso, ter sido provavelmente o centro urbano mais afetado pelo sucateamento da rede pública no Brasil. Na antiga condição de Distrito Federal, o Rio de Janeiro tinha, até duas décadas passadas, grande número de instituições médicas públicas de prestígio, nas quais se baseava o sistema de saúde local. Esta tradição do "serviço público de prestígio" como algo que deveria ser ressuscitado aparece sempre nas entrevistas realizadas com médicos do Rio de Janeiro. A linha do Cremerj não parece ser precisamente esta (como se depreende das falas do seu presidente durante o Fórum Estadual do Sangue), mas dela se aproxima ao defender a necessidade de reaparelhamento do setor público, voltado para a medicina social. Alinha-se com o que é conhecido por "partido sanitarista". Empenha-se em definir uma

28 Entrevista concedida ao Cebrap em 2/3/1989.

29 Observe-se a antiga tradição combativa do Cremerj, que antecede ao surgimento da Aids. 
visão de medicina dentro da sociedade, defendendo o SUDS e a Reforma Sanitária. É dentro desta perspectiva que encara o problema do sangue no estado.

O Cremerj foi responsável pela realização do Forum Estadual do Sangue. Declarava então o presidente do Cremerj, Laerte Vaz de Melo, abrindo os debates: "Nós hoje estamos fazendo um pacto de sangue (...). O sangue reflete a tortura a que foi submemtido o povo brasileiro (...). Se tudo continuar como está, entraremos no ano 2000 sem saber quem nós somos, o que nós somos. (...) Que o Fórum firme este pacto de sangue e a imagem de uma medicina envolvida com a sociedade."

No Boletim do Cremerj 22 (junho 1988), que publica as resoluções finais do forrum, declara o editorial: "Falar da questão do sangue no Brasil é falar de Aids, doença de Chagas, sífilis, malária e, principalmente, da falta de uma política específica para esse setor. Desde que assumimos o Cremerj em 1983, denunciamos a urgente necessidade de haver uma estruturação dos serviços de saúde a fim de que se assegure o sangue à população, com a devida qualidade esperada. Àquela época nos pronunciamos em defesa de serviços de sangue no setor público, integrados, a fim de minorar o risco de doenças transfusionais." O Cremerj posiciona-se em favor da decisão majoritária da Constituinte, afirmando que "o sangue, em qualquer fase de seu processamento, não pode ser mercantilizado". O editorial clama pela decisão política de dignificar o setor, pela participação dos profissionais de saúde na exigência de boa qualidade das atividades hemoterápicas.

No mesmo boletim, o presidente do Cremerj declarava, quanto à responsabilidade profissional diante da transfusão, que o médico, ao prescrever, "deve saber também a procedência do sangue a ser transfundido, além de ter conhecimento acerca do desenvolvimento científico que envolve a questão". Para ele, o fórum serviu para "conscientizar a categoria sobre a problemática atual do sangue, além de reforçar a mobilização em torno da garantia da responsabilidade do Estado no controle de qualidade do sangue através de uma efetiva fiscalização."

O empenho do Cremerj na questão do sangue reflete, sem dúvida, um projeto político mais amplo de um grupo bem representativo de profissionais médicos, projeto em que o acesso da população aos serviços hemoterápicos se articula a uma visão social da medicina, às exigências da democratização política e da busca de melhores condições de vida para a sociedade. Assim definido, tal projeto dificilmente seria recusado, por exemplo, pelos profissionais de antiga militância na SBHH. Entretanto, quando se procura definir a política hemoterápica que deverá rcflctir tal projeto político, as interpretaçoes 
imediatamente divergem e radicalizam-se, não raro contaminadas por projetos de conquista de espaço político pelos partidos políticos à esquerda e à direita.

No caso a seguir examinado - do Sindicato dos Médicos do Rio de Janeiro - , a politização dos debates sobre a hemoterapia transparece com nitidez, pois o Sindicato, pela voz de sua direção, assume posições claras sobre o setor hemoterápico que se chocam, em alguma medida, com as posições dos grupos médicos ligados ao setor privado.

\section{O Sindicato dos Médicos do Rio de Janeiro}

A posição do sindicato dos médicos quanto ao sangue é semelhante à do Cremerj, como se pôde evidenciar durante o Fórum do Sangue no Rio de Janeiro. A participação do Sindicato foi entretanto decisiva, por revelar com maior profundidade as questões em jogo no debate sobre o sangue no Brasil. $\mathrm{O}$ presidente da entidade, o hematologista Crescêncio Antunes da Silveira, foi um dos expositores do Fórum, encarregado do tópico "Doenças transmissíveis e responsabilidade profissional".

Em sua exposição, Crescêncio Antunes ressaltou que, com o progresso da hemoterapiae da tecnologiaindustrial de fracionamento do sangue, ampliouse a aplicação de sangue e derivados na terapêutica médica, levando à comercialização: em torno desse processo científico e dessas possibilidades industriais passou a existir interesse comercial em relação à questão do sangue." Antunes vincula a busca do lucro não tanto ao exercício privado da hemoterapia, mas antes aos interesses industriais que existem na área: "As novas tecnologias aumentaram o valor do sangue para as indústrias de 'ouro vermelho '.(...) Existem hemoterapeutas que merecem o nosso respeito no Rio de Janeiro, porque, mesmo exercendo a hemoterapia em caráter privado, o fazem dentro de critérios estritamente científicos, técnicos e éticos", cabendo a eles "denunciar tudo aquilo de indigno que sabem e conhecem na sua militância do dia-a-dia”.

O presidente do Sindicato dos Médicos considera que dois fatores contribuíram para o problema do sangue no caso brasileiro: a compra de serviços de saúde pela Previdência Social e a indústria de hemoderivados. Quanto ao primeiro, indicou: "A Previdência, remunerando de forma vil os serviços, estimula a corrupção. Não se estimulou (durante o período autoritário) a criação de centros públicos-padrão. A finalidade dos contratos com a rede privada era gerar comissões em dinheiro e votos." Quanto à indústria, assinala que "não é a hemoterapia de rotina que lhe interessa, mas o processo de industrialização. É isto que estimulou a proliferação do bancos clandestinos inteir amente volta- 
dos para o comércio. Sabemos de bancos de sangue que jogavam fora o concentrado de hemácias, porque vendiam só o plasma à indústria."

Em reflexão final sobre o problema, afirma o presidente do Sindicato: "Quando falo da responsabilidade, e agora me dirijo aos médicos, ela é colocada sobre todos os níveis, desde o institucional, governamental, até o médico. (...) O médico brasileiro, de uma maneira geral, não sabe prescrever sangue. É preciso, inclusive, diante da constatação do potencial iatrogênico do sangue, só transfundí-lo se estiver seguro da sua qualidade." E conclui: "é preciso chamar atenção para a responsabilidade ética e criminal do médico que empresta seu nome a um serviço de hemoterapia". (trancrição do Fórum e Boletim do Cremerj 22).

Em outra oportunidade, ${ }^{30}$ Crescêncio Antunes indica que o Sindicato lutou pela emenda aprovada na Constituinte, e que os hemoderivados foram 0 grande problema na votação. Considera que o texto aprovado pela Constituinte levaria à estatização das atividades hemoterápicas, o que porém não impediria o livre exercício da especialidade: "o movimento médico nacional avançou, em anos recentes, defendendo o setor público. Não vou defender a proibição de consultórios particulares em uma sociedade capitalista. Mas que os recursos públicos sejam aplicados no setor público. (...) Os hemoterapeutas querem mesmo o livre exercício e não a estatização. Mas o sanguẹ estatizado não acabaria com o livre exercício. Ele apenas cobraria os honorários médicos para praticar a transfusão. O que ele não pode ser é comerciante de sangue, dono de banco. Mas pode exercer livremente a sua especialidade."

Na mesma oportunidade, Antunes afirmou que o sangue, por sua importância (inclusive em guerras), é uma questão de segurança nacional e um direito da população e que, enquanto houver interesse mercantil, dificilmente haverá uma hemoterapia com segurança para todos. Sobre a nova consciência que se formou sobre a atividade, considera: "nunca se formou um clima de opinião pública como agora. A questão do sangue é crítica no Brasil há muitos anos, mas só com a Aids há sensibilidade. No Rio de Janeiro, a principal causa de Chagas é a transfusão. Em um país como este, terceiro-mundista, com grandes contingentes da população na miséria, nessa indústria voltada para interesses privados vai haver sempre um espaço clandestino para a doação remunerada, porque o plasma é valioso." (grifos nossos) Antunes denunciou o Terceiro Mundo como fonte de matéria-prima para a indústria do plasma, citando os exemplos da Nicarágua de Somoza e o Haiti.

30 Entrevista concedida ao Cebrap em 27/6/1988. 


\section{Outras entidades médicas}

No Estado do Rio de Janeiro. É possível mapear o posicionamento das entidades médicas quanto ao sangue observando que instituições assinam que documentos. A "Carta Compromisso" (15/1/1988) da campanha "Salve o sangue do Povo Brasileiro" (publicada no Boletim do CREMERJ 17), que vinha apoiar o programa de sangue desenvolvido pela Secretaria Estadual de Saúde do Rio de Janeiro, foi assinada pela Federação Nacional dos Médicos, Conselho Federal de Medicina, Cremerj, Sindicato dos Médicos do Rio de Janeiro e Associação Brasileira de Educação Médica (ABEM), além de outras entidades governamentais e não médicas.

Entre as medidas consideradas imediatas, destaca-se a "modernização dos serviços públicos coletores de sangue", a "fiscalização rigorosa de bancos de sangue privados, laboratórios, clínicas e hospitais", e campanhas de esclarecimento de profissionais médicos e da saúde "acerca dos cuidados, deveres e direitos relacionados à qualidade do sangue" e de "doação voluntária de sangue aos serviços não privados". A carta compromisso conclui: "o sucesso desta ação depende da participação ativa e direta da população, no pleno exercício de sua cidadania, resgatando para si o controle dos serviços pelos quais paga e deve ser o único beneficiário."

No Estado de São Paulo. Logo antes da votação da questão do sangue no primeiro turno de votações da Constituinte, o Sindicato dos Médicos de São Paulo publicou nota em jornal (Folha de São Paulo, 14/5/1988), manifestando seu apoio à emenda 2PO-0977-0 (entre outas emendas ao projeto de saúde da Comissão de Sistematização), que veda a comercialização de hemoderivados bem como da coleta e transfusão de sangue, solicitando aos médicos "que se manifestem junto aos senadores e deputados de sua região reivindicando o mesmo".

O informe publicitário "Aids e Bancos de Sangue: de quem é a culpa?" (Folha de São Paulo, 29/1/1988) vinha assinado por várias entidades representantes de hospitais, e, como tal, afinadas com a posição de setores empresariais da classe médica: FENAESS (Federação Nacional dos Estabelecimentos de Serviços de Saúde), Sindicato dos Hospitais do Estado de São Paulo, Federação Brasileira de Hospitais e Associação dos Hospitais do Estado de São Paulo. A nota repudiava veementemente "o uso político-ideológico destas fiscalizações (dos bancos de sangue), pois há alguns diretores e fiscais de centros de saúde que, convocando o jornal, o rádio e a TV, dão entrevistas escandalosas e anti-éticas como se aquilo que eles já deveriam estar fazendo há anos, isto é. fiscalizar. fosse um programa de novela de TV”. O maior res- 
ponsável pela Aids transfusional, segundo a nota, "é o próprio governo", que não autorizou "o pagamento dos testes anti-Aids aos bancos de sangue, dandothes meios de enfrentar seus altos custos adicionais". Descarta-se o problema da Aids transfusional como questão menor. Ao governo, antes de mais nada, caberia "investir maciçamente" e pagar os testes anti-Aids aos bancos de sangue privados.

Esta breve nota sobre outras entidades médicas nos estados de São Paulo e Rio de Janeiro permite visualizar algumas instituições e ações de grupos que, situando-se por vezes à margem das atividades desenvolvidas por órgãos e grupos mais importantes como o Gapa, a SBHH etc, estão invariavelmente alinhadas com uma ou outra destas entidades de maior penetração e impacto político.

Deste quadro que discutimos sobre a participação da sociedade civil sobre a qual voltou-se toda a presente seção - revela-se o entrechoque constante entre posições "socializantes" e "individualistas", as primeiras atribuindo prioridade à saúde coletiva, as demais atentas ao aperfeiçoamento dos serviços de atendimento individual. São duas lógicas de antiga tradição no cenário político brasileiro e que extrapolam o debate sobre o tema da hemoterapia. É um equívoco supor que uma vá prevalecer definitivamente sobre a outra na definição dos rumos das políticas e programas, porque ambas têm defensores encarniçados e compõem verdadeiros blocos de poder no País. No limite como atestam os enormes obstáculos para a regulamentação das leis sobre o sangue e hemoderivados, aprovadas na Constituinte - a radicalização destes blocos políticos poderá conduzir a uma paralisia decisória. Se isto não ocorrer, talvez os rumos da ação política e institucional tendam a um processo de relativa acomodação de interesses, em que as duas posições mencionadas venham a ocupar, de modo a que cedam sem se anularem, papéis de relevo no Sistema nico de Saúde e na política hemoterápica.

A análise da atuação federal, de que tratamos a seguir, aponta para a mesma ordem de problemas e possibilidades: de um lado, a ação governamental encontra-se mais permeável, na atual conjuntura, a um dos grupos de poder; de outro, o processo decisório parece caminhar para um estrangulamento, caso não se estabeleçam canais de comunicação entre os diversos grupos e segmentos da corporação médica que buscam intervir na formulação das políticas públicas. 


\section{Atuação Federal O Planashe}

Uma dos possíveis indicadores da "ação simbólica" do aparelho de Estado é a inesgotável capacidade de criar novos nomes para antigos programas. É o que se deu com o Pro-Sangue em 1988, transformado em Planashe - Programa Nacional de Sangue e Hemoderivados. De novo em relação ao programa antigo houve somente pequenas alterações de rota, que avaliaremos nesta seção.

Quanto ao Pró-Sangue, retomemos algumas características fundamentais. O Programa em curso durante quase toda a década de 80 norteou a presença do Estado como executor de uma política centralizada e a criação de hemocentros como a espinha dorsal desta política. Indicamos, em seção anterior, que em larga medida o Pró-Sangue foi a resposta oficial às pressões de setores da sociedade civil, particularmente da corporação médica, pela melhora de qualidade da atividade hemoterápica - esta, por sua vez, prejudicada de modo perverso pela própria política do Inamps, que comprava sangue de forma negligente e indiscriminada junto a bancos particulares.

O Planashe é na verdade o Pró-Sangue com outro nome, sem mudanças profundas que justificassem esta alteração. Se houve alteração, ela teve $o$ propósito de criar um "fato novo" no cenário da hemoterapia brasileira, diante da intensa e vigorosa articulação de movimentos sociais criados após o aparecimento da Aids no Brasil.

A força da política hemoterápica governamental durante a segunda metade da década - independentemente dos nomes que recebeu - esteve associada ao impacto da Aids transfusional sobre segmentos da sociedade civil. A criação do Planashe como "fato novo" se explicaria: a política hemoterápica estatal da Nova República procurou influenciar - mais precisamente, aquietar - as opiniões profundamente críticas e o generalizado sentimento de revolta dos movimentos sociais emergentes diante do surgimento da Aids transfusional, que intensificou o "medo social" provocado pela doença. Ainda que não excluísse a atuação sobre o cenário da hemoterapia - dando sequiência às iniciativas anteriores à Nova República - a política governamental pós-Aids buscou atuar sobretudo no plano dos sentimentos e da percepção dos segmentos sociais organizados. ${ }^{31}$

31 Confrontem-se os trabalhos de Murray Edelman sobre a ação governamental como estímulo à "cognição política", afetando os sentimentos e comportamentos dos indivíduos. Veja-se, especialmente, Politics as Symbolic Action. New York: Academic Press 1971 
O Planashe foi elaborado pela Divisão Nacional de Sangue e Hemoderivados (órgão do Ministério da Saúde), que deve articular recursos de quatro ministérios (Previdência e Assistência Social, Trabalho, Educação e Ciência e Tecnologia), Seplan e Secretarias Estaduais, além de buscar recursos junto a entidades internacionais (como a Opas e o Banco Mundial) para garantir os fundos que o tornem exeqüível. Neste aspecto, o Plano é mais complexo que o Pró-Sangue, pois busca diversificar as fontes de financiamento disponíveis.

$\mathrm{O}$ documento de criação do Planashe busca definir um programa complexo, detalhado e exeqüível. Este esforço compreende desde objetivos amplos - como a implantação de uma rede nacional de hemocentros, a criação de uma infra-estrutura laboratorial, a interiorização dos serviços de hemoterapia, a produção de hemoderivados, $\mathrm{o}$ incentivo à pesquisa $\mathrm{e}$ a autonomia financeira dos hemocentros - até traços específicos, como a implantação de um projeto de uniformização da imagem do sistema como um todo, o controle de qualidade dos insumos básicos para a área e a integração dos hemocentros em uma rede nacional informatizada. Assim, também no plano dos objetivos programáticos, o Planashe é sem dúvida mais completo que o Pro-Sangue, já que aponta para uma extensa gama de questões absolutamente relevantes para o desenvolvimento de um sistema hemoterápico eficiente. Um ponto de extrema relevância é a regulamentação de uma avaliação periódica do programa. Esta avaliação será feita através de visitas da Dinashe, de reuniões trimestrais das coordenadorias regionais e de reuniões semestrais dos diretores de hemocentros e representantes dos ministérios envolvidos.

Se, de um lado, o Plano explicita e amplia certas tendências importantes do programa anterior, permanecem no Planashe limitações sérias do Pro-Sangue, como a formulação de uma política de cima para baixo, que passa dos orgão federais aos estaduais e municipais sem buscar uma composição mais efetiva com os setores que já atuam na área. Tome-se, nesse sentido, a definição restritiva de democratização proposta no Planashe. Ela abarca a participação da população e a presença regional, no espírito da descentralização proposta pelo SUDS, mas não faz qualquer menção aos setores privados cuja atuação na área é antiga e responsável. Finalmente, observe-se que ainda são um tanto genéricas as recomendações contidas no novo Plano. Nele, não se definem as atividades que serão desenvolvidas, para além das recomendações sempre imprecisas de "implementar", "estimular", etc. 


\section{O sistema em funcionamento: linhas gerais}

Os avanços na hemoterapia brasileira, consolidados ao longo da década de 1980, e os problemas cruciais que ainda enfrenta, podem ser avaliados a partir do trabalho coordenado por Sérgio Henrique Ferreira (da Faculdade de Medicina Ribeirão Preto/USP e Fiocruz) e publicado sob o título "O Brasil precisa de sangue", na revista Ciência Hoje $)^{32}$. Escrito em um momento em que o setor já se sentia ameaçado pela operação (raramente criteriosa) de enxugamento administrativo e financeiro das empresas estatais, este excelente trabalho trás um conjunto de informações até então pouco sistematizadas, fundamentais para um esforço de planejamento da atividade hemoterápica brasileira, além de um balanço a respeito do número e das atividades dos hemocentros já instalados.

Algumas tabelas de Ciência Hoje permitem visualizar a situação do sistema hemoterápico público, com a oferta de sangue por ele suprida em comparação com a demanda nacional, os custos de uma transfusão dentro da rede oficial de hemocentros, um mapa com o programa de expansão e interiorização da rede pública, além de um claro organograma dos serviços a serem hierarquizados e descentralizados.

O país conta hoje com 35 hemocentros instalados em suas principais cidades. A cobertura hemoterápica oferecida por estes hemocentros ainda varia muito, chegando a $100 \%$ em alguns estados como o Pará e o Amazonas, enquanto em outros como a Bahia, mal atinge os $10 \%$. Em São Paulo a cobertura oficial chega a $60 \%$, em Minas Gerais a $50 \%$ e no Rio de Janeiro responde a apenas $30 \%$ da cobertura hemoterápica total (ibidem).

$\mathrm{O}$ quadro revela que em alguns estados a ação federal tem enorme relevância, sendo absolutamente necessária sua existência. Em áreas onde o processo de estadualização das políticas de sangue já estava em curso observase uma composição entre as políticas federal e estadual. Este é o caso, por exemplo, de São Paulo, onde desde 1987 se estabeleceu uma ação conjunta do chamado Gepro do Sangue (Grupo Especial de Programas de Hematologia e Hemoterapia) e da coordenadoria para a região Sudeste da Dinashe (Divisão Nacional do Sangue e Hemoderivados, do Ministério da Saúde). Nestas áreas em que a "estadualização" se fez presente as políticas públicas não apresentam efeito preponderantemente simbólico - como"em boa parte, se deu com as políticas do Pró-Sangue e do Planashe - mas produzem efeitos concretos sobre a qualidade e abrangência dos serviços.

32 "O Brasil precisa de sangue", Ciência Hoje, SBPC, abril de 1989, 9 (52), pp.45-61. 
Em relação à indústria de hemoderivados há alguns indicadores importantes no trabalho de Ciência Hoje. Estima-se que o Hemope (o hemocentro estatal de Pernambuco), o Instituto Santa Catarina e alguns laboratórios privados produzam apenas $10 \%$ dos hemoderivados necessários para atender à demanda nacional. A produção do setor público se restringe hoje ao Hemope e à esperança de que a entrada em funcionamento da planta de albumina de Brasília conquiste a auto-suficiência regional, além do desenvolvimento de uma tecnologia que poderá ser repassada para outros centros. A importação maciça e o gasto de divisas garantem o suprimento de $90 \%$ dos hemoderivados necessários ao País.

Quando comparado ao inicío dos anos 80, o quadro mais recente evoluiu bastante. Há, no entanto, uma enorme distância entre a capacidade instalada do setor público, suas perspectivas de financiamento e a demanda efetiva por serviços e produtos hemoterápicos. A qualidade dos serviços exige atenção constante e redobrada: por efeito das políticas estaduais e federais no setor hemoterápico (e diante do apoio, em anos recentes, de programas federais não diretamente vinculados à hemoterapia, como os desenvolvidos pela Divisão de Doenças Sexualmente Transmissíveis, do Ministério da Saúde) já se nota uma tendência declinante nos casos de doenças causados por transfusão de sangue contaminado. ${ }^{33}$ Os primeiros sinais positivos de melhora não podem, entrentanto, produzir um afrouxamento na vigilância sanitária e epidemiológica. A atividade hemoterápica sofreria imediatamente uma queda no padrão alcançado nos últimos anos, se ocorrer um afrouxamento da polícia sanitária.

Do lado do setor privado, apresenta-se um novo perfil, particularmente a partir de 1987. Os pequenos bancos desprovidos de qualidade vão sendo fechados pela Vigilância Sanitária, sob pressão da sociedade e num contexto de certa vontade política governamental. Restam em operação os serviços de porte médio, ligados a hospitais privados ou centros hematológicos e que, em alguns casos, representam os chamados serviços de primeira linha. (Em São Paulo este quadro é mais nítido, sobressaindo-se o Hospital Israelita Albert Einstein, o Sírio Libanês e o Santa Catarina.) Estes serviços garantem a qualidade do sangue aos que podem pagar com recursos próprios ou - caso mais freqüente - com os recursos de convênios. As transfusões autólogas e

33 Veja-se o cuidadoso levantamento de Maria Ignez Duque Estrada, "Cresce a ameaça da Aids no Brasil", publicado em Ciência Hoje, janeiro/fevereiro de 1989, 9 (50), pp. 70-72. O trabalho baseia-se em entrevista e dados concedidos por Lair Guerra de Macedo Rodrigues, coordenadora nacional da campanha contra a Aids ao tempo da publicação do trabalho em Ciência Hoje. 
casadas são comuns ali, bem como o uso de materiais importados, de padrão de qualidade aprovado internacionalmente.

Uma nota final, mas não menos importante, diz respeito à própria escassez de dados, no Brasil, sobre a atividade hemoterápica. Nesta escassez reside um indicador sociológico preocupante. Se trabalhos como o que abordamos (em Ciência Hoje) são raros na literatura nacional; se pesquisadores brasileiros raramente conduzem estudos e surveys sobre as instituições e serviços hemoterápicos, sobre o perfil do doador, sobre tipos ou sistemas de doação no Brasil e no exterior; se as bibliotecas de sindicatos, associações, instituições de pesquisa e faculdades de medicina têm pouquíssima literatura internacional sobre o tema - como se poderá conduzir seriamente um debate sobre a atividade hemoterápica no país e propor rumos para os próximos anos? Como se poderá regulamentar a própria matéria constitucional, recentemente aprovada? Tudo indica, a nosso ver, que não há como afastar, no momento, a probabilidade de que se tomem decisões e se estabeleçam políticas desprovidas do necessário embasamento empírico. ${ }^{34}$

\section{Conclusões}

Este estudo pretendeu apontar a relação entre política estatal, sociedade e hemoterapia no Brasil durante os anos 80 . No período militar, na verdade desde seu início, a atividade hemoterápica aflorou como tema de segurança nacional. Mas foi apenas durante a década de 1980, mais precisamente a partir de 1985, que o tema se tornou objeto de ampla discussão, envolvendo, pela primeira vez, segmentos representativos da sociedade civil. O aparecimento da Aids transfusional no Primeiro Mundo e, logo em seguida, no Brasil, atraiu o interesse nacional sobre a qualidade do sangue e dos hemoderivados.

O debate político sobre o tema - agora uma "questão" controversa, mais do que mero tema de interesse - intensificou-se e polarizou-se, afetando o próprio debate político-partidário nacional sobre o Estado e os grupos empresariais, e sendo por sua vez afetado por este debate mais amplo, com suas virtudes e seus cacoetes.

Neste contexto, particularmente no período conhecido como Nova República, o tema passou a ocupar um espaço político dentro do setor estatal ligado

34 Por exemplo, muito se diz que o que exportamos de plasma poderia suprir as necessidades nacionais para a produção de hemoderivados. Jamais se apresentaram os dados que balizassem tais afirmações. Se elas forem incorretas, passa a ser uma ficção supor que a eliminação das exportações — ou contrabando? — permitiria atender à demanda interna. 
à saúde. O Programa Nacional do Sangue (Pró-Sangue) foi o primeiro sinal efetivo de intervenção estatal. Apesar da conquista de um espaço político, ausente no caso das políticas anteriores, o Pró-Sangue não desempenhou plenamente as atividades para as quais foi criado. A idéia, que só em parte vingou, era de que toda a organização hemoterápica seria gerida pelo Estado a partir de um sistema único, organizado por princípios de máxima racionalidade técnica e social.

Na década de 1980, a Aids foi um divisor de águas por atrair a atenção nacional para a gravidade da contaminação sanguínea. Apesar de várias endemias no Brasil estarem vinculadas à transfusão de sangue contaminado, a infecção pelo HIV teve o agravante de causar uma doença quase sempre terminal, disseminada por todas as classes e idades, tanto na população masculina como feminina. O Plano Nacional de Sangue e Hemoderivados (Planashe), do governo federal, foi a nova denominação que a política hemoterápica recebeu em resposta ao agravamento dos riscos transfusionais. No plano estadual, houve programas mais agressivos e eficazes, que, atuando em conjunto com programas do Ministério da Saúde, foram responsáveis por mudanças substanciais no padrão da atividade hemoterápica - impacto produzido, por exemplo, pela atuação do Grupo Especial de Desenvolvimento de Programa de Hematologia e Hemoterapia (o "Gepro do Sangue"), em São Paulo, a partir de 1987.

Este trabalho procurou indicar que a necessária discussão do desempenho de diferentes modelos hemoterápicos em diferentes países, e do modo pelo qual as atividades e responsabilidades do setor hemoterápico estão distribuídas entre os setores público e privado, deve preceder à definição dos rumos da hemoterapia no Brasil. Se este amplo e cuidadoso estudo não for conduzido por grupos de trabalho multiprofissionais, tanto da área pública como privada, as políticas para o setor tenderão a tomar rumos puramente político-ideológicos, de corte partidário ou sectário.

Este tópico permite uma conclusão fundamental, de natureza política: não há como tratar a questão do sangue - como de resto qualquer outra política pública - com a "ideologização" que caracterizou os debates e as conclusões mais importantes da Assembléia Constituinte em relação à saúde. Nossa discussão procurou apontar a extrema diversidade e complexidade do setor do sangue. Neste sentido, a insistência em se decretar soluções extremas nos parece ser o ponto nodal que tem dificultado sobremaneira a busca de um consenso minímo sobre os rumos da hemoterapia brasileira. Acreditamos que o sistema deva ser único e abrangente, mas sem perder a eficiência e o dinamismo. Ao se socializarem partes do sistema não se deve excluir toda a ação privada do setor, 
ao se centralizarem certos serviços não se deve eliminar a atuação hospitalar, ao se incentivar a doação voluntária, a necessária discussão moral não deve ignorar as distorções e riscos que o recurso ao pool comunitário poderá gerar.

O conjunto destas questões é da maior importância para se avaliar não só o modelo hemoterápico que se deseja implantar no País e, de forma descentralizada, em cada Estado, como para formular uma política de hemoderivados. Isto porque toda a política industrial tem que enfrentar o problema da obtenção de matéria-prima, que se resolve, por sua vez, no interior da própria política hemoterápica.

Em um próximo trabalho procuraremos trazer uma contribuição para o debate, abordando certas dimensões institucionais e técnicas, discutidas pela literatura internacional, que consideramos pouco conhecidas no País. Do ponto de vista institucional — onde é maior a lacuna nos debates - , acreditamos que as múltiplas combinações em que aparecem no Primeiro Mundo as dimensões do "público" e do "privado", da centralização e da descentralização, da doação altruísta e da doação remunerada, devem ser examinadas detidamente pelos "atores" da política hemoterápica e pelos movimentos sociais. ${ }^{35}$

A questão da doação, em particular, além de exigir o exame detido da literatura internacional, merece ser abordada do ponto de vista sociológico em trabalhos de pesquisa com o universo de doadores no Brasil - objeto que tem estado além das cogitações e propósitos dos debatedores da "questão do sangue" em nosso país, e que pretendemos focalizar oportunamente. Um aspecto final é da ordem dos valores éticos da sociedade brasileira, em que doadores socialmente destituídos doam, na verdade por preços vis, o que não deveriam doar. Por outro lado, as exigências do setor que consome e demanda sangue provêm em boa parte das necessidades criadas pelas modernas tecnologias médicas, que são por sua vez aplicadas às populações médias e altas, jamais dispostas a doar sangue. É sobre esta população que as políticas públicas e os movimentos sociais deveriam centrar seu foco de atenção, de maneira a reorientar as normas e valores que afetam o comportamento desta população socialmente privilegiada.

35 Em recente estudo, Vera Schattan P. Coelho discute, do ponto de vista da organização adotada, do tipo de capital e da natureza da doação, a diversidade das combinaçõs que uma política hemoterápica pode assumir, traçando em seguida os possíveis contornos de um modelo para o Brasil. Veja-se "Gestão pública versus gestão privada do sangue: oposição ou complementaridade”. São Paulo: Fundap, 1991 (mimeo). 


\section{RESUMO}

\section{Os Anos 80: a Politização do Sangue}

Este trabalho focalizou o impacto da Aids sobre os caminhos da hemoterapia brasileira, de um duplo ponto de vista: em primeiro lugar, do ângulo das políticas públicas, tanto federais (Pró-Sangue e Planashe) quanto estaduais (Grupos de Desenvolvimento de Programas); em segundo lugar, do ângulo da eclosão de movimentos sociais e grupos de pressão (como a Abia e o Comitê "Pacto de Sangue") - manifestações sem precedentes da sociedade civil na história das lutas pela saúde no Brasil. Estas manifestações, segundo acreditamos, foram em grande parte responsáveis pelas primeiras conquistas reais no tocante à melhora dos serviços hemoterápicos e ao ordenamento e controle da produção industrial de hemoderivados. As políticas públicas para todo o conjunto das atividades durante os últimos anos na verdade responderam àquelas pressões, em contraste com o processo anterior de formulação de políticas, em que o Estado tomava decisões independentemente da sociedade civil (menos dos setores empresariais, aos quais se mostrou por demais permeável) e tomava a iniciativa.

A politização da questão do sangue produziu benefícios indiscutíveis, no contexto mais amplo do grande debate nacional provocado pela entrada da Aids no País, e pelo "grande medo" que a epidemia desencadeou em toda a população. A atividade hemoterápica chegou a ser contemplada na legislação votada pela Assembléia Constituinte de 1988, tamanha foi a projeção que o tema alcançou, na esteira das discussões sobre a Aids.

Mas houve problemas evidentes na legislação aprovada na Constituinte, em parte decorrentes da necessária e bem-vinda politização do tema. $\mathrm{O}$ avesso do debate político, por assim dizer, foi sua excessiva "ideologização", acompanhada da ausência de discussão sobre as experiências ou modelos hemoterápicos internacionais. Esta discussão teria, a nosso ver, matizado o conteúdo doutrinário dos debates sobre as questões da estatização ou privatização, centralização total ou descentralização radical, doação altruísta ou doação remunerada. Em um próximo artigo em Physis procuraremos focalizar estes tópicos e tirar, do debate internacional e da diversidade das soluções institucionais ali encontradas, algumas lições para a experiência brasileira. 


\section{ABSTRACT}

\section{From Human Blood to Politics: the Impact of AIDS in Brazil}

This paper focuses on the extraordinary impact of Aids on blood-related policies in Brazil during the late 1980's. The threat of acquiring the HIV through blood transfusions, combined with the widespread social fear of contracting the global disease, triggered an unprecedented array of social movements and non-government agencies demanding improved, safer, and more ethical blood banking and production of plasma fractions. In fact, there were pressing demands of popular opinion and the press since the late 1970's and early 1980's against the transmission of infectious diseases by blood transfusion, such as doença de Chagas and hepatitis. Such pressures brought about some tightening of federal inspection and the launching of a National Blood Program, known as Pró-Sangue, in 1980. But these measures had little impact on the quality of services, compared with later developments during the decade.

The spread of Aids through transfusion attracted national attention to institutional and political problems of the blood and plasma production sectors. The population at large joined the groups and movements created on the wave of that debate. The political parties followed suit. The federal government yielded to pressures by developing new policies for the sector in 1988, more comprehensive and a bit more effective than the older programs. However, real progress in the creation of regional and state-funded blood centers, in the quality-control of blood, and in the adoption of strict standards for the plasma market was only achieved when state governments (such as the states of São Paulo and Rio de Janeiro) took the lead and worked together with the Ministry of Health authorities. But much remains to be done from the point of view of medical inspection and legal control, especially in some Brazilian states where action is heavily dependent on the federal government.

From a broader point of view, a complete overhauling of the system of blood donation and production of plasma fractions is expected. The Aids debate highlighted several institutional problems of that system that cut across very old, unsettled political issues in Brazil, such as state control vis-à-vis private control, federal centralization vis-à-vis regional decentralization, the (un)fairness of public subsidies to profit-making firms and activities, etc. These are proper concerns and should be pursued. However, the discussion of these issues has been soaked in too much ideology and petty politics, particularly during the debates of the National Constitution Assembly of 1988. What we argue is that the legislation approved by the Constitution - which still needs 
specific definition of rules and regulations - lacked proper consideration of technical and institutional problems affecting the blood donation system and the plasma market. We also argue that the workshops, conferences and public debates preceding the Assembly meetings did not benefit from, or took advantage of, the lessons contained in the vast literature regarding the international experience, in all its diversity.

In a future issue of Physis, we expect to make an effort in considering the international experience. We will review the international literature on relevant technical and institutional dimensions of blood-related policies and programs, and discuss those specific topics that bear upon Brazil's particular case.

\section{RESUME}

\section{Les années 80: la politisation du sang}

Le SIDA a eu au Brésil un impact certain sur les procédures liées à l'hémothérapie. Le présent travail met ceci en relief à un double égard. Il prend d'abord en considération les politiques publiques, qu'elles se situent au niveau de la fédération (comme c'est le cas pour le Pró-Sangue ou le Planashe) ou des états (avec les Groupes de Développement de Programmes). Mais il fait également état de l'éclosion de nombre de mouvements sociaux et de groupes de pression liés a ce problème (comme, par exemple, l' Abia et le Comité "Pacte du Sang") ainsi que de manifestations originaires de la société civile. Celles-ci n'ont aucun présédent dans l'histoire des luttes pour la santé au Brésil. C'est, nous le croyons, en grande partie, grâce à ces manifestations que survinrent les premières conquètes réelles en ce qui concerne l'amélioration des services d'hémothérapie, ainsi que la mise en ordre et le contrôle de la production industrielle d'hémodérivés. Les politiques publiques concernant l'ensemble de ces activités constituent en vérité, au cours des dernières années, une réponse à ces pressions. Le processus actuel de formulation de ces politiques contraste en ce sens avec celui de la période précédente, lorsque l'Etat prenait les décisions indépendamment de la société civile et se trouvait à l'origine des initiatives. (Il faut toutefois excepter ici le secteur industriel, au désir duquel l'Etat ne se montra que trop perméable).

La politisation de la question du sang a donné lieu à des acquis indiscutables qu'il faut re-situer dans un contexte plus ample: celui de l'intense débat qu'a provoqué au plan national l'entrée du SIDA dans le pays. L'épidémie a en effet suscité une "grande peur" au sein de toute la population. Les 
discussions sur le SIDA ont mis en relief les activités liées à l'hémothérapie avec une ampleur telle que celles-ci firent l'objet d'un ensemble spécial de lois votées au cours de l'Assemblée Constituante de 1988.

Mais cette législation suscite des problèmes aujourd'hui évidents qui sont en partie dús à la politisation - pourtant nécessaire et oportune - du thème qui lui est lié. On peut dire que le revers de cette politisation a été une "idéologisation" excessive doublée d'une totale absence de discussion quant aux modèles hémothérapeuthiques internationaux. Celle-ci aurait permi à notre avis de nuancer le contenu théorique des débats sur certaines questions: étatisation ou privatisation, centralisation totale ou descentralisation radicale, don altruiste du sang ou don rémunéré.

Nous publierons dans un prochain numéro de Physis un article où nous proposons de focaliser ces aspects. Ils ont suscité au plan international des débats et des solutions dont nous nous efforcerons de tirer les leçons pour les pratiques à être mises en oeuvre au Brésil. 
